\title{
Entsisewata'karí:teke (You Will Be Healthy Again): Clinical Outcomes of Returning to a Traditional Haudenosaunee Diet
}

\author{
Russell J. de Souza, Nicole M. Bilodeau, Kelly Gordon, A. Darlene Davis, Jennifer C. Stearns, Mary \\ Cranmer-Byng, Katie Gasparelli, Lori Davis Hill, Sonia S. Anand
}

\author{
A R T I C L E IN F O
}

Keywords:

Haudenosaunee

Indigenous

Six Nations of the Grand River

Traditional diet

Body weight

Blood pressure

Hemoglobin A1c

Visceral fat

https://doi.org/10.32799/ijih.v16i2.33098

\author{
A B S T R A C T
}

\section{A U THOR IN F O}

Haudenosaunee Peoples of eastern North America have a strong agricultural tradition and culture associated with maize horticulture. Traditional foodways and diet were disrupted after the people were dispossessed from traditional lands maintained prior to colonization. As a result, Haudenosaunee have been disconnected from their traditional diet and lifestyle, and chronic diseases such as diabetes and obesity are increasing. Healthy Roots was developed in Six Nations of the Grand River territory by Haudenosaunee community members. It started as a 90-day challenge, in which participants adhere to a diet of traditional foods found in Haudenosaunee territories pre-European contact. The community decided to formally evaluate the impact of the diet in a pilot pre-post intervention study of 22 participants in 2016/17. We investigated the effects of the 3-month dietary intervention on physical measurements, ectopic fat (including visceral and liver adipose tissue), serum lipids, and hemoglobin A1c among Haudenosaunee participants in Six Nations. We provided biweekly Haudenosaunee food boxes, and offered workshops, cooking classes, and individual support from a dietitian. The intervention reduced body weight, body circumferences including waist circumference, hemoglobin A1c, and MRI-detected hepatic fat fraction. There were no adverse events. Engagement in the program was high and trends favoured improved well-being. The intervention shows great potential as a mechanism for improving physical health and restoring cultural connectedness and identity. The implications for improving mental health and community cohesion are also important areas to consider in future research.

Russell J. de Souza, RD, ScD, Associate Professor, Department of Health Research Methods, Evidence, and Impact, McMaster University, Hamilton, Ontario, Canada. Specializing in nutrition epidemiology. Primary author and data analyst for the paper. Email: desouzrj@mcmaster.ca

Nicole M. Bilodeau, MA, Six Nations Health Services, Ohsweken, Ontario, Canada. Co-author of the paper and freelance writer.

Kelly Gordon, RD, Six Nations Health Services. Co-author of the paper who is a dietitian and helped conceive and design the Healthy Roots Challenge and Research Study. She collected data, facilitated workshops, and provided dietary counseling.

Darlene Davis, RN, Six Nations Health Services. She is Wolf Clan. Co-author of the paper and research nurse. She coordinated clinic visits, obtained informed consent, performed physical measurements, collected and processed biological samples, collected case report forms, and booked MRI visits. 
Jennifer C. Stearns, PhD, Departments of Medicine and Gastroenterology, McMaster University. Co-author of the paper and the Farncombe Family Chair in Microbial Ecology and Bioinformatics. She provided insight into the biological sample collection protocols.

Mary Cranmer-Byng, MSc, RD, Six Nations Health Services. Co-author of the paper who is a dietitian and helped conceive the Healthy Roots Challenge and Research Study. She collected data, facilitated workshops, and provided dietary counseling.

Katie Gasparelli, PT, MSc, Six Nations Health Services. Co-author of the paper who provided administrative support for the project.

Lori Davis Hill, MHSc, is the Director of Six Nations Health Services. Co-author of the paper and participated in the community challenge. She championed and provided administrative and financial support for the project.

Sonia S. Anand, MD, PhD, Professor of Medicine and Epidemiology, Department of Medicine, McMaster University, Hamilton, Ontario, Canada. Co-author of the paper and the principal investigator of the Canadian Alliance of Healthy Hearts and Minds, which provided infrastructure support for this project. She helped facilitate this research connection, by virtue of her strong history of working with Six Nations of the Grand River.

\section{Acknowledgements}

As is customary in Haudenosaunee tradition, we first must give thanks to everything in creation that continues to support us. We gratefully acknowledge Iethi'nisténha Onhwéntsial (Mother Earth) for providing us with kahnekahrónnion (waters), tsi tkahén:taien (fields), tsi tkahéhtaien (gardens), karhahrónnion (woods), and tsi tkaronhiá:te (skies). We also give thanks to all kontírio (the animals), kaienthóhsera (the harvest), and tionnhéhkwen (the life sustainers) for continuing to provide us with what we need to survive.

We also acknowledge all onkwehshòn:'a (the people), especially Ohswekenhró:non (people of Six Nations of the Grand River), who contributed to and participated in the Healthy Roots challenges. This study was supported by Six Nations Health Services, which provided dietetic services and food baskets to the participants. We also greatly appreciate the partnership and collaboration with McMaster University for making the clinical study possible, including funding provided through the Canadian Alliance for Healthy Hearts and Minds (CAHHM).

\section{Introduction}

The Haudenosaunee are also known as the Six Nations or Iroquois, and comprise the Mohawk, Cayuga, Oneida, Seneca, Onondaga, and Tuscarora Nations of eastern North America. Despite hundreds of years of colonial policies and practices aimed at destroying Indigenous societies, our communities still maintain many of our cultural traditions.

It is well established that there are great health disparities between Indigenous Peoples living in Canada and the rest of the population (Adelson, 2005), such as higher cardiovascularrelated death rates (Park et al., 2015; Reading, 2015; Tjepkema et al., 2012) and prevalence of diabetes and obesity (First Nations Information Governance Centre, 2018; Gionet \& Roshanafshar, 2013). Often the cause of these health issues is grossly oversimplified by stating that it is merely due to factors such as dietary acculturation, sedentary lifestyle, or lack of access

\footnotetext{
${ }^{1}$ The words written in italics are in Kanien 'kéha (the Mohawk language)
} 
to healthy foods, which all contribute - but the causes are much more complex than this. Land dispossession and disconnection from our foods and food system are important influences (Patchell \& Edwards, 2014).

The Haudenosaunee had a strong agricultural tradition pre-contact, based primarily on maize horticulture as evidenced by the vast number of varieties that were cultivated over centuries (Waugh, 1916). Our system of agriculture is most well known for companion planting, which we refer to as Áhsen Nikontate'kèn:'a (Three Sisters) and which has two main components: intercropping ó:nenste (corn), ohsahè:ta (beans), and onon'ónsera (squash) together, and planting in mounds (DeCaire, 2012; Mt. Pleasant, 2016). This is a complex and sophisticated agricultural system that is more productive than monoculture cropping and does not require chemical fertilizers and pesticides (Mt. Pleasant \& Burt, 2010). In addition, during the 17th and 18th centuries, Haudenosaunee farmers were 3 to 5 times more productive than their European counterparts, despite farming without plows or draft animals (Mt. Pleasant, 2011). This demonstrates the level of sophistication of Haudenosaunee agricultural practices.

Our relationship to food reflects our deep-seated cultural values about how we relate to and engage with the land. Seeing the land as something that we have a "right" to or "ownership" over reflects a fundamentally different worldview compared to one that sees the earth as our Mother, giving us an inherent responsibility to care for everything in creation. The cultural mechanism for maintaining a relationship to land and food is through ceremony. We have over 20 yearly ceremonies, the majority of which are giving thanks to or honouring different aspects of the natural environment, many specifically related to food (maple sap, strawberries, raspberries, beans, green corn, fall harvest, etc.). Corn, beans, and squash are important parts of our creation story and are specifically acknowledged in our Thanksgiving Address. In short, a foundational aspect of Haudenosaunee culture is honouring food. Practising these ceremonies on a regular basis fosters the development of a mindset that inherently honours food and land.

Our traditional foods are also of high nutritional quality. We prepare maize through a process called nixtamalization, cooking the kernels in hardwood ash to release the hard outer hull. Preparing maize in this way increases the amount and quality of essential minerals and vitamins (Mt. Pleasant, 2016). Regularly consuming corn, beans, and squash together is a nutrient-dense diet that meets basic energy and protein requirements and provides a complete amino acid profile (Lewandowski, 1987; Mt. Pleasant, 2006, 2016). A recent study found that the phenolic composition of purple maize had significant anti-inflammatory, anti-adipogenic, and anti-diabetic effects (Zhang et al., 2019). A study of the phenolic properties of a diet consisting of maize, beans, and pumpkin has shown the potential to control glucose absorption, postprandial hyperglycemia, and hypertension linked to diabetes because of the antioxidant properties of these foods (Kwon et al., 2007). Therefore, returning to a traditional diet could potentially contribute to reducing the risk and impact of chronic diseases such as diabetes.

Healthy Roots is a community-based dietary intervention, originally developed by the community, which aims to return Haudenosaunee Peoples to a traditional diet in order to become healthy again (Gordon et al., 2018). The impetus for this study was that participants in the 
Healthy Roots challenge on Six Nations of the Grand River territory saw such remarkable results from returning to a traditional Haudenosaunee diet that they called for a formal scientific investigation.

\section{Methods}

\section{Participants}

Participants were recruited in October 2016 through posters, word of mouth, community events, and community newspaper advertisements. The study began December 1, 2016, and participants were followed through July 31, 2017. We recruited 22 individuals (21 women and 1 man), 18 years of age and older $(M=45.3$ years, $S D=11.9)$ to participate in this study. We jointly recruited participants for this study and the Canadian Alliance for Healthy Hearts and Minds (CAHHM), which was designed to better understand the impact of individual, socioeconomic, and other environmental factors leading to cardiac and vascular disease. Individuals were ineligible to participate if they were pregnant or had chronic disease (e.g., cancer, established cardiovascular disease, diabetes longer than 5 years), metal implants, or a body size too large to fit in a magnetic resonance imaging (MRI) scanner. All participants were volunteers and free to withdraw at any time. Upon arrival, but prior to any clinical assessment and/or questionnaire completion, study personnel conducted an informed consent discussion with each participant.

\section{Study Design}

Participants were observed for two consecutive 3-month periods, as depicted in Figure 1. During the first ("control") period, participants followed and recorded their food intake and lifestyle pattern. During the second ("Healthy Roots" intervention) period, participants followed the Healthy Roots program, and recorded their food intake and lifestyle pattern. Measurements were taken at three time points: (a) before beginning observation under the control period; (b) during the final week of the control period; and (c) during the final week of the Healthy Roots intervention period. 


\section{Figure 1}

Study Design

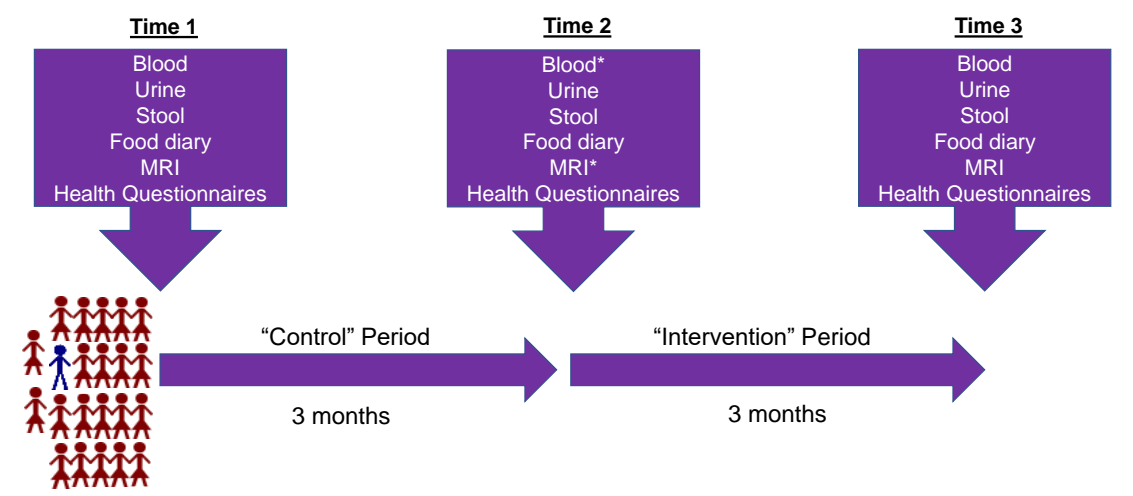

Note: At the middle visit, only 10 participants attended the MRI scan and provided valid measurements, and only nine participants provided a blood sample.

\section{Intervention}

This was a single group, pre-post study design. The study had two 3-month periods: (a) a control ("usual diet") period; and (b) an intervention ("Healthy Roots") period. The dietary intervention was based on the Haudenosaunee Food Guide developed for the Healthy Roots challenge (Gordon et al., 2018). This diet emphasizes foods that are cultivated and prepared in the traditional Haudenosaunee territory, using traditional ways of gathering and food preparation. Participants were provided with a list of traditional foods from which to eat, which fell into five categories:

- from the woods (e.g., venison, walnuts, maple syrup)

- from the water (e.g., rainbow trout, yellow perch, walleye, wild rice)

- from the skies (e.g., duck, turkey, and their eggs)

- from the garden (e.g., white corn, kidney beans, varieties of squash)

- from the meadow (e.g., blackberries, blueberries, honey, Jerusalem artichoke)

A basket containing a variety of these traditional foods was provided to participants every 2 weeks. Participants were encouraged to only consume foods that were original to the lands on which the Haudenosaunee live and to avoid processed foods, specifically the "five white gifts" of sugar, salt, lard, dairy, and wheat. This approach to choosing foods would be expected to make up a whole diet high in protein and fiber, and low in refined carbohydrate. Two community dietitians facilitated educational sessions and workshops, including cooking and food preparation classes, and provided instructions on how to collect and shop for Haudenosaunee foods.

\section{Data Collection}

Both community and academic partners shared control of resources and review processes, the planning process, and management of the information. The physical data were initially stored at Six Nations Health Services, and transported to and stored at McMaster University (Hamilton, Ontario) and the Population Health Research Institute (Hamilton Health Sciences Corporation, 
Hamilton, Ontario). This process was covered through an existing protocol and agreement between Six Nations of the Grand River and McMaster University through the Canadian Alliance for Healthy Hearts and Minds.

\section{Physical Measures}

At the beginning of the control period, each participant underwent a baseline evaluation of physical measurements (e.g., height; body weight; blood pressure; pulse; arm, neck, chest, calf, thigh, waist, and hip circumference; percent body fat by bioelectrical impedance scale). At the end of the control period, on the day that the participants started the dietary intervention, these measures were repeated. These measures were again repeated at the end of the Healthy Roots period. The full details of the physical measurement protocol have been published (Anand et al., 2016).

\section{Biological Samples}

Most, but not all, participants agreed and were able to provide blood samples for glycosylated hemoglobin (HbA1c), apolipoprotein B (Apo-B), apolipoprotein A1 (Apo-A1), and creatinine ( $n=21$ at the beginning of the usual diet period, $n=9$ at the beginning of the Healthy Roots period, and $n=16$ at the end of the Healthy Roots period). All participants $(n=21)$ provided urine samples for long-term storage at the three time points. An MRI scan to determine the presence of ectopic adipose tissue in the abdominal viscera including the liver and heart was collected at most visits ( $n=21$ at the beginning of the usual diet period, $n=10$ at the beginning of the Healthy Roots period, and $n=14$ at the end of the Healthy Roots period), though the number of people with complete MRI scans of all fat depots was less than this. The full details of the physical measurement and MRI protocol have been published (Anand et al., 2016). ${ }^{1}$

\section{Questionnaires}

At all three visits (or the last two in the case of self-reported mental health), we had participants fill out surveys to assess seven domains of health:

1. Chronic pain. We used a 10-item visual analogue scale for assessing the severity of chronic pain (Von Korff et al., 1992). The score ranged from 0 (no pain) through 10 (worst possible, unbearable, excruciating pain).

2. Dietary intake. Participants completed a 3-day prospective food record during both "usual diet" and intervention diet periods in the week prior to each clinic visit.

3. Satiety, gas, and bloating. Participants completed forms we have used in previous studies (Wong et al., 2010; Zulyniak et al., 2016) to record their overall feeling of satiety using a 9-point bipolar semantic scale in which -4 was excessively hungry, 0 was neutral, and +4 was uncomfortably full. Gas and bloating were assessed on

\footnotetext{
${ }^{1}$ A detailed description of sample collection, analysis, and storage procedures is in Appendix A (physical measures) and Appendix B (biological samples).
} 
a 3-point scale in which -1 was less than usual, 0 was as usual, and +1 was more than usual.

4. Diet palatability. Palatability was assessed on a form used in previous studies (Wong et al., 2010; Zulyniak et al., 2016) on a scale of 1 (not palatable) to 10 (highly palatable).

5. Bowel habits. Participants recorded the number of bowel movements, and any episodes of diarrhea and/or constipation, on a form we have used in previous studies (Wong et al., 2010; Zulyniak et al., 2016).

6. Self-reported mental health. Participants completed the PHQ-9 mental health questionnaire (the 9-item depression module of the Patient Health Questionnaire; Kroenke et al., 2001) twice - at the beginning and end of the intervention period. The PHQ-9 assesses mental well-being, and scores range from 0 to 27 , with higher scores meaning worse mental health.

7. Estimated 10-year risk of a cardiovascular event. The INTERHEART cardiovascular risk score is a measure of 10-year cardiovascular disease risk that considers medical history, cigarette smoking, stress, physical activity, diet, and waist and hip circumferences (available at https://rome.phri.ca/interheartriskscore; McGorrian et al., 2011; see also Appendix B).

\section{Statistical Considerations}

\section{Power and Sample Size}

For this study, a sample size of 15-20 people was determined to be feasible such that detailed assessments could be undertaken while retaining the close relationship with participants necessary to deliver the Healthy Roots intervention. Data from previous studies conducted with the Six Nations population were used to estimate the means, standard deviations, and withinsubject correlations used in the following effect size calculations. An intraclass correlation coefficient of .925 was assumed for repeated measures based on previous data collected from the Study of Health Assessment and Risk Evaluation (Anand et al., 2000), the Study of Health Assessment and Risk Evaluation in Aboriginal Peoples (Anand et al., 2001), the Multicultural Community Health Assessment Trial (Lear et al., 2007), and baseline data from the Canadian Alliance for Healthy Hearts and Minds cohort, which is now published (Anand et al., 2019).

The co-primary outcomes of this study were body weight $(\mathrm{kg})$ and waist circumference (cm). Important secondary outcomes were hemoglobin A1c (HbA1c), liver fat (expressed as the hepatic fat fraction [HFF, \%]), and visceral adipose tissue volume (mL). For this study, 20 paired measures provided $80 \%$ power to detect meaningful differences between treatments in changes in body weight (mean difference $[M D]=4.8 \mathrm{~kg}, S D=7.0)$, waist circumference $(M D=3.8 \mathrm{~cm}$, $S D=5.5), \mathrm{HFF}(M D=1.7 \% ; S D=2.5)$ and visceral adipose tissue $(M D=14.9 \mathrm{~mL} ; S D=21.5)$, if each tested separately with a paired-samples $t$ test at a significance level of $p<.05$ (Statulator, 2014). Data were analyzed using SAS (Version 9.4). 


\section{Assessment of Treatment Differences in Physical and Metabolic Risk Factors}

The difference in change scores between the Healthy Roots period and the control period for each variable was the measure of effect, and was calculated for body weight, waist circumference, $\mathrm{HbAlc}$, and liver fat, as well as other physical and biological measures. The significance of the difference in change scores (Healthy Roots minus control) was assessed using a paired-samples $t$ test on change scores. The significance of changes in count variables was assessed using Fisher's exact test because many cell counts were less than 5. No adjustment for multiple testing was undertaken for this study. We also report changes and differences as Cohen's $d$ (Cohen, 1988), to help the reader assess the magnitude of the changes in terms of $S D$ units. Absolute values of $d$ less than 0.2 are considered to indicate small effects; between 0.2 and 0.8 medium; and greater than 0.8 large. With a Cohen's $d$ of $0.8,78.8 \%$ of the Healthy Roots measurements would be above the mean of the control period measurements, and there was a 71.4\% chance that a measurement picked at random from the Healthy Roots period would have a higher score than a measurement picked at random from the control period (probability of superiority; Sullivan \& Feinn, 2012; https://rpsychologist.com/cohend/). With a Cohen's $d$ of $0.2,57.9 \%$ of the Healthy Roots measurements would be above the mean of the control period measurements, and there was a $55.6 \%$ chance that a measurement picked at random from the Healthy Roots period would have a higher score than a measurement picked at random from the control period.

\section{Relationship}

Participants in the first two Healthy Roots challenges had such positive experiences that the community decided it was important to further investigate the impact of a traditional Haudenosaunee diet on physical health through a clinical study. The community and the researchers at the university partnered to conduct the study at the community's request. The partners have a 25-year history of working together; however, this study was the first time the research was community-driven and -led. In the manuscript we have used the term "our" in several places. We as the Haudenosaunee community leads (Davis Hill, Bilodeau, Davis, Gasparelli, and Gordon) want the paper to reflect the deep community-led component. Therefore, we use "our," even though some of the authors (de Souza, Anand, Cranmer-Byng, and Stearns) are not Haudenosaunee. The use of "our" is inclusive because this partnership has respected and facilitated a voice for our community. The authors made every effort to represent the voice of the community in this paper.

\section{Ethics Approval and Registration}

This study was approved by the Six Nations Council Research Ethics Committee (November 8, 2016; Resolution no.: EC\#001 - 11/08/2016) and the Hamilton Integrated Research Ethics Board (Project \#13-255, 9/28 2016). The Canadian Alliance for Healthy Hearts and Minds is registered with clinicaltrials.gov (NCT02220582). 


\section{Results}

Aggregate results were shared with participants after this study was completed, through a sharing circle and two formal presentations by community and academic partner researchers. Each participant received a copy of his or her personal study results, which was reviewed with them by a study nurse or dietitian, with the ability to contact study staff for further clarification at any time in the future. We also presented the results of the study to the community at large, which was also open to Health Services staff during Community Awareness Week (2018), to be inclusive of community members who were not participants in the study. A future event is planned to share these results with health care staff.

\section{Baseline Characteristics}

Of the 40 participants we approached to participate, 22 agreed (Figure 2) and their baseline characteristics are summarized in Table 1. The participants had a mean age of 45.3 years $(S D=11.9)$ at the baseline visit, with a mean body mass index $(B M I)$ of $37.0 \mathrm{~kg} / \mathrm{m}^{2}(S D=$ $4.0)$, and mean waist-to-hip ratio of $0.92(S D=0.07)$. Twenty-one of 22 participants $(95 \%)$ identified as women. The mean values of biological markers of disease risk (e.g., blood pressure, Apo-B, Apo-A1) and physical measures (e.g., height, weight, circumference measures) are provided in Table 1. The average baseline INTERHEART risk score was $13.7(S D=5.6$; available for $n=20$ ). Five participants $(25 \%)$ were classified by this score to be low risk ( $M=$ $6.8, S D=0.8)$, six participants $(30 \%)$ were moderate risk $(M=12.7, S D=2.1)$, and 9 participants $(45 \%)$ were high risk $(M=18.2, S D=4.1)$. Nine participants had taken at least 1 prescription medication during the preceding 3 months to control cardiovascular risk factors $(n=$ $5)$ and other conditions $(n=8)$. 


\section{Figure 2}

CONsolidated Standards of Reporting Trials, CONSORT 2021 Flow Diagram

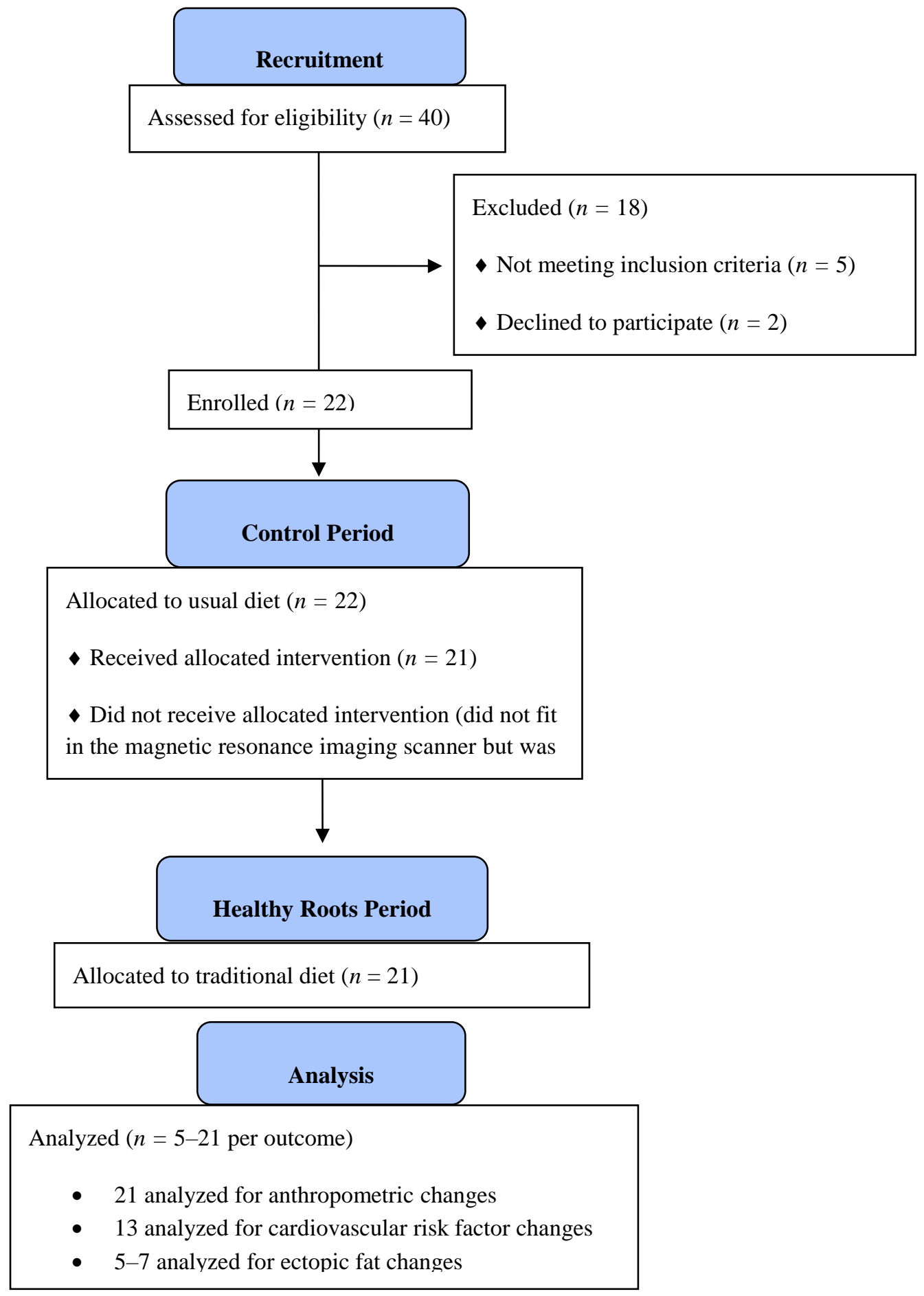

Note. This flow diagram illustrates the progression through the periods of this trial. 


\section{Table 1}

Baseline Characteristics of the Study Participants

\begin{tabular}{|c|c|c|c|}
\hline Characteristic & $N$ & $M$ & $S D$ \\
\hline \multicolumn{4}{|c|}{ Physical measures } \\
\hline Age & 22 & 45.3 & 11.9 \\
\hline Number identifying as women (\%) & 22 & $21(95 \%)$ & - \\
\hline Number of smokers (\%) & 22 & $0(0 \%)$ & - \\
\hline Height $(\mathrm{cm})$ & 22 & 163.6 & 7.0 \\
\hline Weight (kg) & 22 & 98.9 & 12.1 \\
\hline Body mass index & 22 & 37.0 & 4.0 \\
\hline Body fat (\%) & 22 & 47.0 & 2.8 \\
\hline Waist circumference $(\mathrm{cm})$ & 22 & 109.3 & 9.7 \\
\hline Hip circumference $(\mathrm{cm})$ & 22 & 118.4 & 7.4 \\
\hline Waist-to-hip ratio & 22 & 0.92 & 0.06 \\
\hline Mid-upper arm circumference $(\mathrm{cm})$ & 22 & 34.2 & 4.3 \\
\hline Calf circumference $(\mathrm{cm})$ & 22 & 40.4 & 3.9 \\
\hline Chest circumference $(\mathrm{cm})$ & 22 & 114.5 & 7.9 \\
\hline Neck circumference $(\mathrm{cm})$ & 22 & 36.5 & 3.1 \\
\hline Thigh circumference $(\mathrm{cm})$ & 22 & 57.0 & 5.3 \\
\hline Total body circumference $(\mathrm{cm})^{\mathrm{a}}$ & 22 & 510.3 & 28.0 \\
\hline \multicolumn{4}{|c|}{ Cardiovascular risk factors } \\
\hline Systolic blood pressure (mmHg) & 22 & 129.4 & 16.2 \\
\hline Diastolic blood pressure (mmHg) & 22 & 80.3 & 9.9 \\
\hline Heart rate $(\mathrm{bpm})$ & 22 & 69.2 & 12.9 \\
\hline Creatinine $(\mu \mathrm{mol} / \mathrm{L})^{\mathrm{b}}$ & 21 & 70.7 & 12.5 \\
\hline Apolipoprotein B (Apo-B; g/L ) ${ }^{b}$ & 21 & 0.99 & 0.19 \\
\hline $\begin{array}{l}\text { Apolipoprotein A1 (Apo-A1; g/L) } \\
\text { b }\end{array}$ & 21 & 1.38 & 0.25 \\
\hline Apo-B:Apo-A1 ${ }^{\mathrm{b}}$ & 21 & 0.74 & 0.19 \\
\hline Hemoglobin A1c $(\%)^{b}$ & 21 & 5.7 & 0.6 \\
\hline \multicolumn{4}{|c|}{ Ectopic adipose tissue measures ${ }^{c}$} \\
\hline $\begin{array}{l}\text { Subcutaneous adipose tissue } \\
\text { (SAT; mL) }\end{array}$ & 12 & 228.2 & 52.2 \\
\hline $\begin{array}{l}\text { Visceral adipose tissue (VAT; } \\
\mathrm{mL} \text { ) }\end{array}$ & 18 & 103.3 & 37.3 \\
\hline SAT:VAT ratio & 12 & 2.6 & 1.3 \\
\hline $\begin{array}{l}\text { Cardiac adipose tissue (CAT; } \\
\mathrm{mL} \text { ) }\end{array}$ & 17 & 23.2 & 7.9 \\
\hline Hepatic fat fraction (HFF; \%) & 20 & 11.8 & 10.7 \\
\hline
\end{tabular}

${ }^{a}$ Total body circumference is the sum of waist, hip, mid-upper arm, calf, chest, neck, and thigh circumferences. ${ }^{\mathrm{b}}$ One participant did not provide a blood sample at either pre-study visit. ${ }^{\mathrm{c}}$ 12-20 participants provided valid images for ectopic fat depots at the pre-study visit. 
Participants consumed a mean of 1,915 kcal/day $(S D=537): 16.5 \%$ from protein, $46.0 \%$ from carbohydrate, $37.5 \%$ from fat (12.1\% saturated and $0.5 \%$ trans), and $21.1 \mathrm{~g}$ dietary fibre per $2,000 \mathrm{kcal}$ at baseline (Table 2). Alcohol consumption was low in this sample: 8 out of 22 participants reported some alcohol consumption during the pre-study period, averaging 2-4 drinks/month. There were no significant changes in self-reported dietary intake, physical measures, and most cardiovascular measures during the control period (Appendix $\mathrm{C}$ ). The exception was a change in Apo-A1 of $-0.08 \mathrm{~g} / \mathrm{L}(95 \% \mathrm{CI}:-0.15$ to $-0.01 ; p<.01)$.

\section{Table 2}

Nutrient Composition of Diets in the Control and Healthy Roots (Intervention) Periods

\begin{tabular}{|c|c|c|c|c|c|}
\hline Nutrient & $\begin{array}{l}\text { Control } \\
(n=16) \\
M(S D)\end{array}$ & $\begin{array}{c}\text { Healthy Roots } \\
(n=15) \\
M(S D) \\
\end{array}$ & $\begin{array}{c}\text { Healthy Roots minus } \\
\text { Control }(n=14) \\
M(95 \% \text { CI })\end{array}$ & Cohen's $d$ & $p$ value \\
\hline Energy (kcal) & $1,915(537)$ & $1,821(559)$ & $-253(-608,101)$ & -0.41 & .15 \\
\hline Protein (\% of energy) & $16.5(4.1)$ & $20.8(5.6)$ & $5.1(1.3,8.9)$ & 0.77 & .01 \\
\hline Carbohydrate $(\%)$ & $46.0(6.0)$ & $43.1(8.3)$ & $-4.7(-10.0,0.5)$ & -0.52 & .07 \\
\hline Dietary fibre $(\mathrm{g} / 2,000 \mathrm{kcal})$ & $21.1(5.8)$ & $26.4(8.0)$ & $5.1(0.7,9.5)$ & 0.67 & .03 \\
\hline Sugar (g/day) & $88.3(28.0)$ & $78.3(49.1)$ & $-21.8(-49.1,5.6)$ & -0.46 & .11 \\
\hline Added sugar (g/day) & $19.9(29.9)$ & $14.2(16.5)$ & $-8.7(-28.9,11.6)$ & -0.25 & .37 \\
\hline Fat $(\%$ of energy) & $37.5(6.6)$ & $36.0(6.7)$ & $-0.4(-4.7,4.0)$ & -0.05 & .86 \\
\hline Saturated (\% of energy) & $12.1(3.5)$ & $7.8(2.4)$ & $-3.9(-5.8,-1.8)$ & -1.11 & .001 \\
\hline Monounsaturated (\% of energy) & $11.5(2.9)$ & $11.3(4.5)$ & $0.3(-2.7,3.2)$ & 0.06 & .85 \\
\hline Polyunsaturated (\% of energy) & $6.6(1.8)$ & $10.8(3.3)$ & $4.2(2.2,6.1)$ & 1.27 & $<.001$ \\
\hline $\begin{array}{l}\text { Trans-unsaturated (\% of } \\
\text { energy) }\end{array}$ & $0.5(0.4)$ & $0.2(0.2)$ & $-0.3(-0.5,0.2)$ & -1.00 & .001 \\
\hline n-6:n-3 fatty acids $(g / g)$ & $9.5(3.3)$ & $10.6(3.3)$ & $1.6(-3.4,6.6)$ & 0.19 & .50 \\
\hline $\begin{array}{l}\text { Polyunsaturated:Saturated fat } \\
(\mathrm{g} / \mathrm{g})\end{array}$ & $0.6(0.2)$ & $1.5(0.7)$ & $0.9(0.5,1.3)$ & 1.50 & $<.001$ \\
\hline Cholesterol (mg/day) & $276(135)$ & $358(286)$ & $91(-52,235)$ & 0.37 & .19 \\
\hline $\begin{array}{l}\text { Vitamin A (retinol active } \\
\text { equivalents) }\end{array}$ & $495(286)$ & $724(670)$ & $244(-49,538)$ & 0.48 & .09 \\
\hline $\begin{array}{l}\text { Folate (dietary folate } \\
\text { equivalents) }\end{array}$ & $309(144)$ & $288(144)$ & $-66(-156,23)$ & -0.43 & .13 \\
\hline Vitamin C (mg/day) & $99(64)$ & $118(97)$ & $-10(-44,24)$ & -0.17 & .55 \\
\hline Calcium (mg/day) & $664(318)$ & $412(170)$ & $-299(-511,-97)$ & -0.85 & .007 \\
\hline Iron (mg/day) & $12(4)$ & $15(5)$ & $2.0(-1.4,5.4)$ & 0.34 & .22 \\
\hline Magnesium (mg/day) & $228(77)$ & $340(146)$ & $80(6,154)$ & 0.63 & .04 \\
\hline Phosphorus (mg/day) & $996(312)$ & $1,185(495)$ & $115(-186,416)$ & 0.22 & .42 \\
\hline Potassium (mg/day) & $2,347(799)$ & $3,033(1,643)$ & $296(-482,1,074)$ & 0.22 & .43 \\
\hline Sodium (mg/day) & $3,513(1,717)$ & $1,737(921)$ & $-2,036(-3,122,-949)$ & -1.08 & .001 \\
\hline
\end{tabular}

Note. Sixteen participants provided food records at either or both pre-study visits; 15 participants provided food records during Month 3; and 14 participants returned food records at at least one pre-study visit and at the Month 3 visit. 


\section{Post-Intervention Changes}

\section{Dietary Profiles}

The Healthy Roots diet resulted in modest decreases in total energy, carbohydrate, saturated and trans fat, and sodium; and increases in polyunsaturated fat, dietary fibre, and magnesium (Table 2).

\section{Physical Measures}

We observed significant changes in physical measures on Healthy Roots, compared with the control period. Body weight fell by $4.3 \mathrm{~kg}(d=-0.98 ; p<.0001)$, BMI by 1.6 units $(d=$ $-0.99 ; p<.0001)$, and waist circumference by $5.4 \mathrm{~cm}(d=-1.21 ; p<.0001)$, which were all large effect sizes (Figure 3). We observed a trend favouring lower percent body fat by $1.0 \%$ points (95\% CI: -2.1 to $0.2 ; d=-0.42 ; p=.09$ ) on Healthy Roots. Overall, a large change in body circumference $(M=-16.6 \mathrm{~cm} ; 95 \% \mathrm{CI}$ : -21.9 to $11.4 ; d=-1.27)$ was seen on Healthy Roots, driven by lower waist $(p<.0001)$, hip $(p<.01)$, chest $(p<.004)$, thigh $(p<.007)$, and calf $(p<.09)$ circumferences (Figures 3 and 4$)$. The waist-to-hip ratio was unchanged $(p=.11)$.

\section{Figure 3}

Between-Treatment Differences in Weight, Waist Circumference, and Body Mass Index

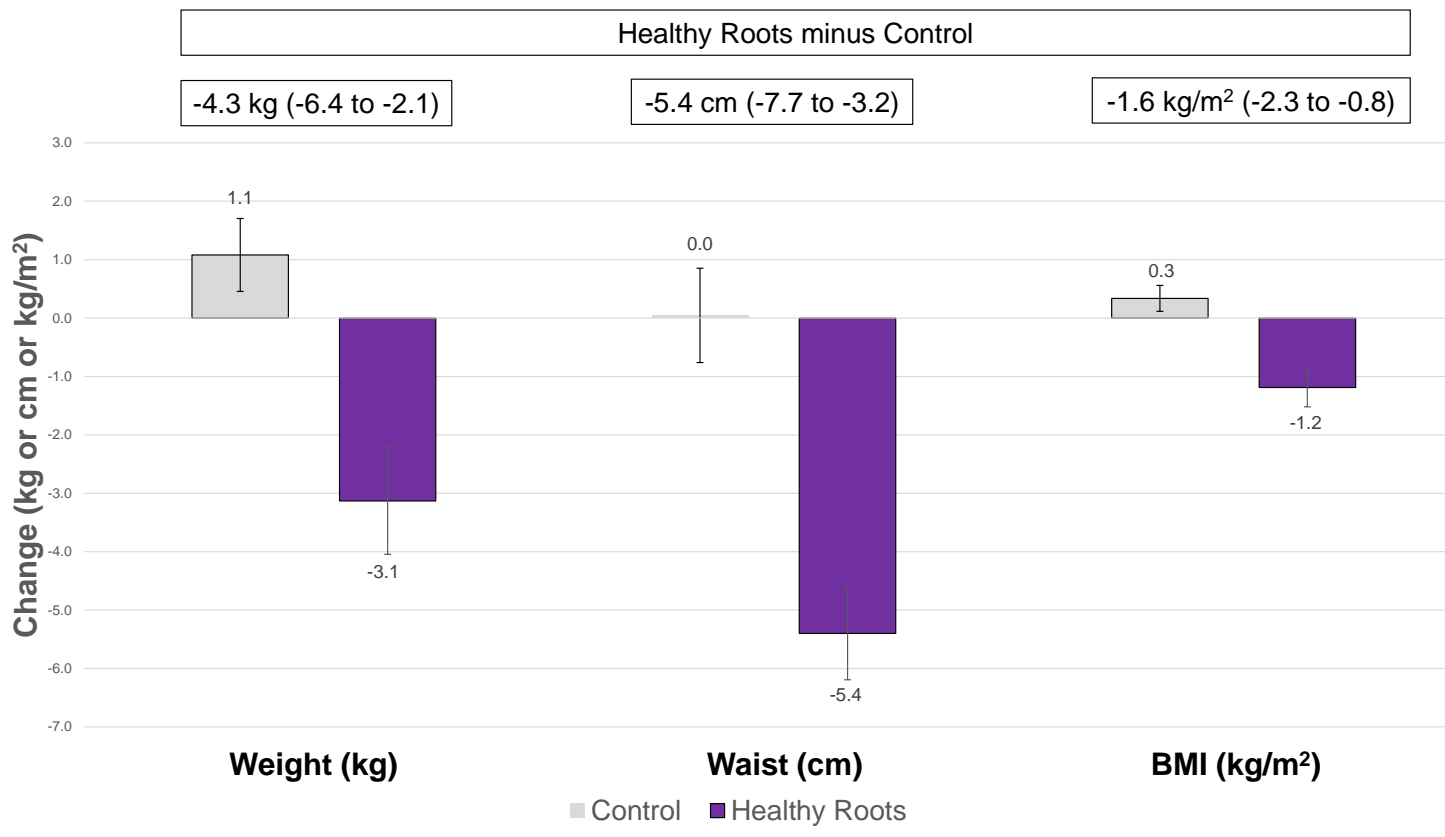

Note. The first value in the box is the mean difference (Healthy Roots minus Control). Values in parentheses are the upper and lower 95\% confidence limits of the mean difference. Bars display within-group changes. The mean difference may not precisely match the difference of the values displayed on the bars due to rounding, and because only 18 pairs of measures were used for the ttest. The error bars represent standard errors. 


\section{Figure 4}

Between-Treatment Differences in Hip, Waist, Arm, Chest, Thigh, and Calf Circumferences

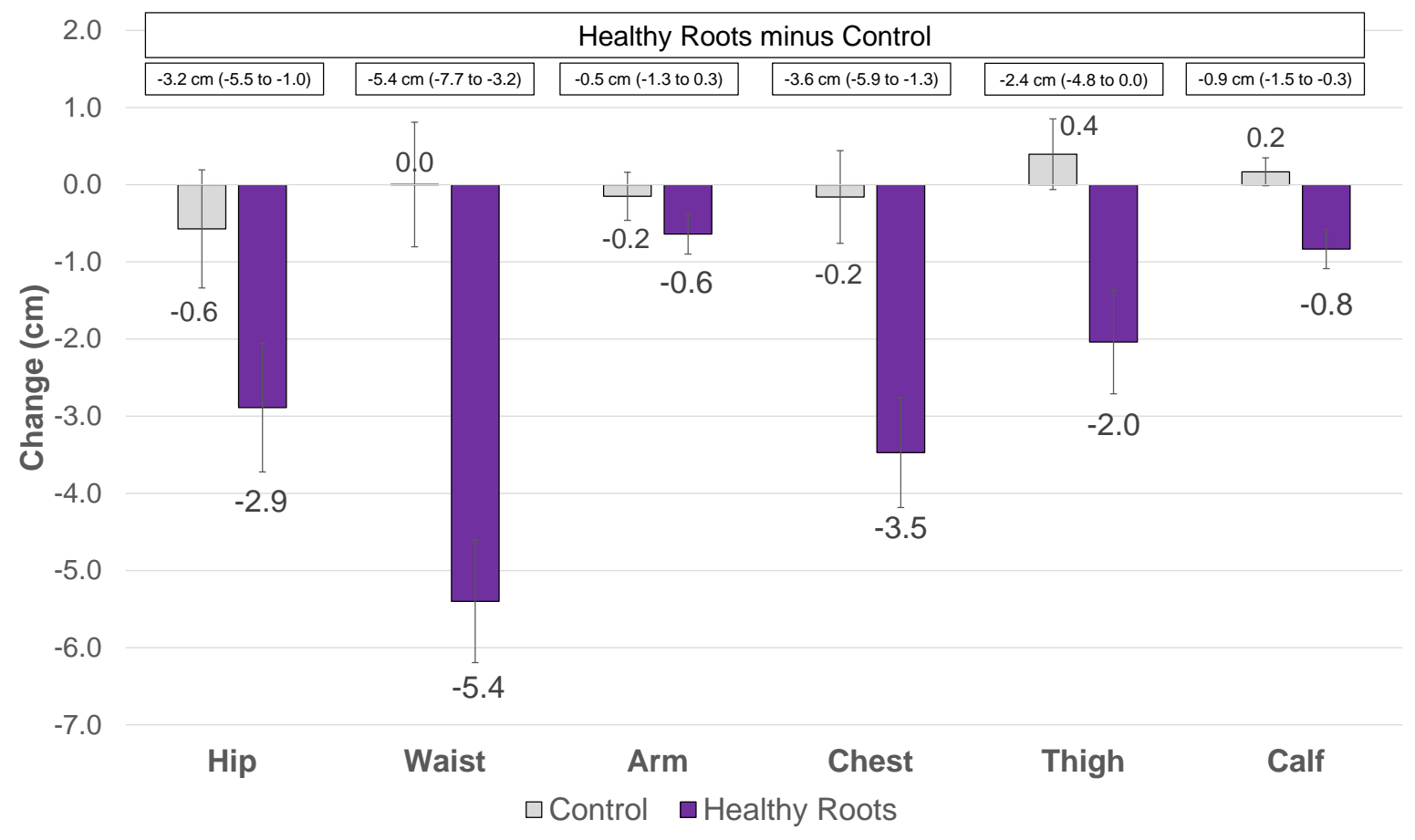

Note. The first value in the box is the mean difference (Healthy Roots minus Control). Values in parentheses are the upper and lower $95 \%$ confidence limits of the mean difference. Bars display within-group changes. The mean difference may not precisely match the difference of the values displayed on the bars due to rounding, and because only 18 pairs of measures were used for the ttest. The error bars represent standard errors.

\section{Blood Pressure and Heart Rate}

There were no statistically significant differences in change scores between the Healthy Roots and control periods with respect to systolic $(d=0.07 ; p=.76)$ or diastolic $(d=0.03$; $p=.89)$ blood pressure, or heart rate $(d=-0.37 ; p=.13)$.

\section{Lipid and Glycemic Risk Factors}

We observed significant changes in the blood lipid profile during the Healthy Roots period, compared with the control period. Apo-A1, a marker of a healthy blood lipid profile, did not differ in change between groups $(d=-0.19 ; p=0.59)$; but Apo-B, a marker of unhealthy blood lipid profile, increased by $0.19 \mathrm{~g} / \mathrm{L}(d=1.37 ; p=.003)$ and the Apo-B:Apo-A1 ratio increased by 0.12 units $(d=1.12 ; p=.047)$ in the Healthy Roots period compared with the control period (Figure 5). These results were not materially different when we removed two participants with outlying values (>2 SD in magnitude, and directionally inconsistent with others for that period mean) for changes in Apo-A1 and Apo-B, nor after we adjusted for length of 
fasting prior to blood sample collection. HbA1c decreased by $0.20 \%$ points $(d=-1.27 ; p=0.01$; Figure 6).

\section{Renal Biomarkers}

No statistically significant difference in change score between the Healthy Roots and control periods were observed with respect to creatinine $(d=-0.31 ; p=.38)$.

\section{Figure 5}

Between-Treatment Differences in Apo-A1, Apo-B, and Apo-B:Apo-Al Ratio

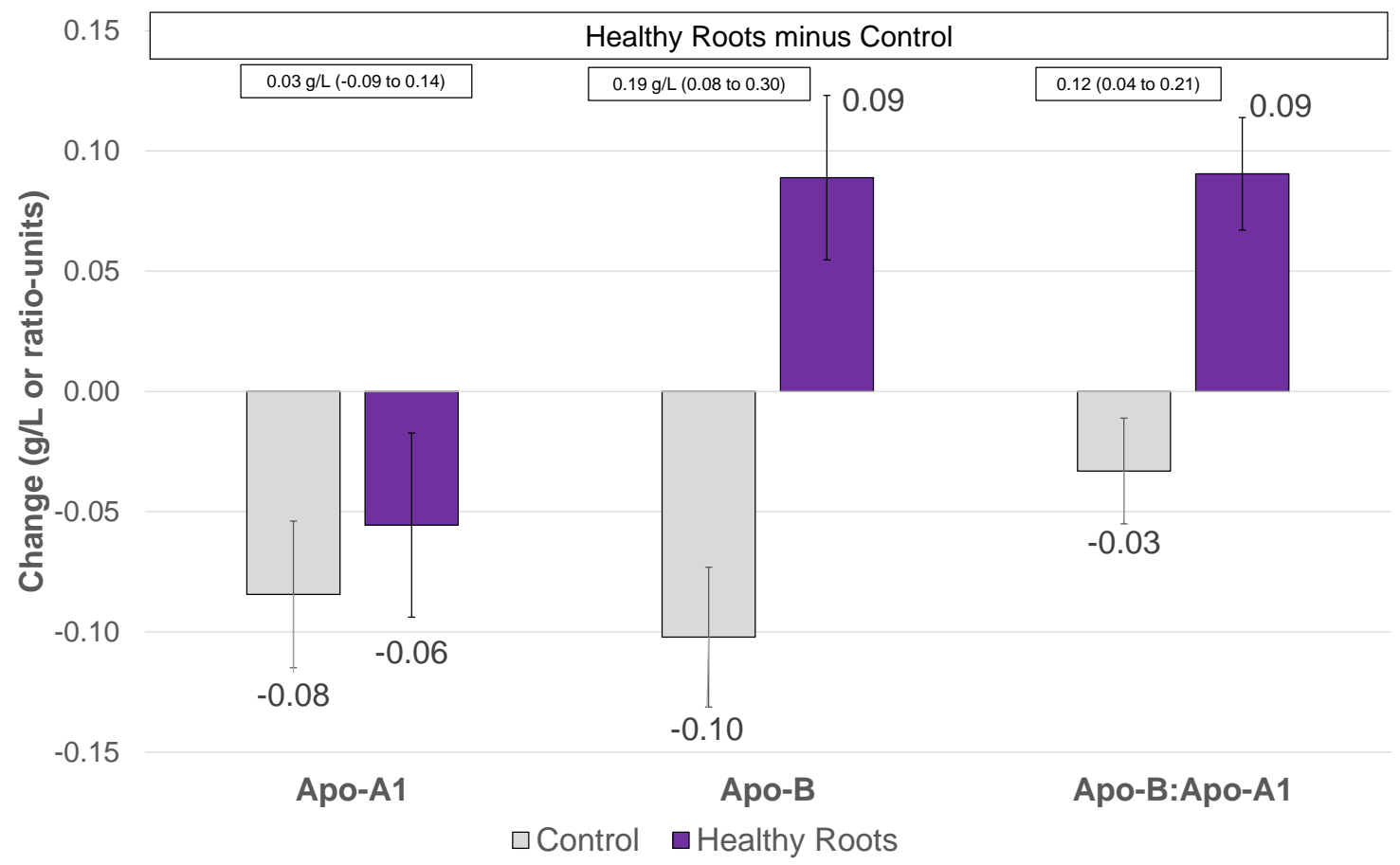

Note. The first value in the box is the mean difference (Healthy Roots minus Control). Values in parentheses are the upper and lower 95\% confidence limits of the mean difference. Bars display within-group changes. The mean difference may not precisely match the difference of the values displayed on the bars due to rounding, and because only 9 pairs of measures were used for the ttest. The error bars represent standard errors. Apo = apolipoprotein. 


\section{Figure 6}

Between-Treatment Difference in glycosylated hemoglobin (HbAlc)

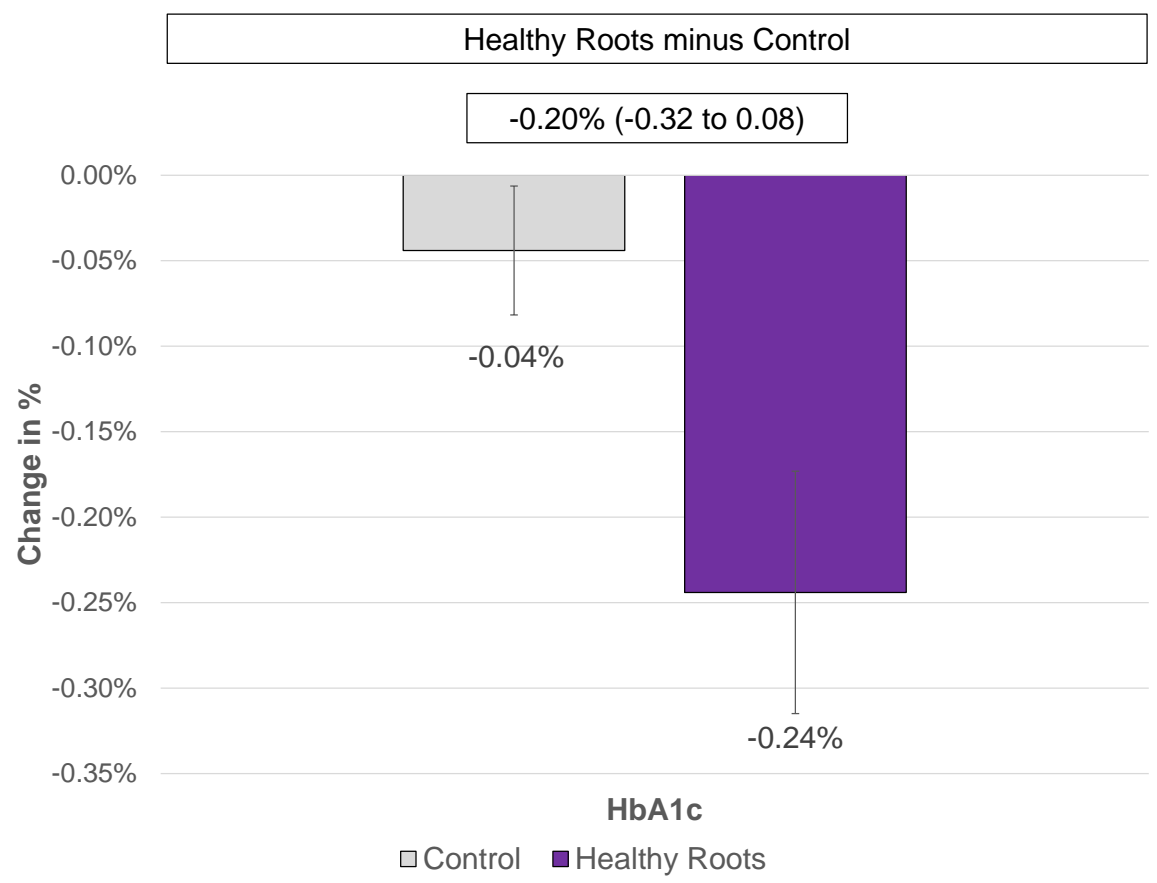

Note. The first value in the box is the mean difference (Healthy Roots minus Control). Values in parentheses are the upper and lower $95 \%$ confidence limits of the mean difference. Bars display within-group changes. The mean difference may not precisely match the difference of the values displayed on the bars due to rounding, and because only 9 pairs of measures were used for the ttest. The error bars represent standard errors.

\section{Ectopic Adipose Tissue}

Twenty participants had MRI abdominal scans at Month -3, 10 at Month 0, and 13 at Month 3. No statistically significant differences in change scores between the Healthy Roots and control periods were observed with respect to volumes of abdominal fat volume measures: subcutaneous adipose tissue (SAT; $d=-0.62 ; p=.30 ; n=4$ paired measures), visceral adipose tissue (VAT; $d=0.26 ; p=.55 ; n=6$ paired measures); or cardiac adipose tissue (CAT; $d=$ $-0.28 ; p=.52 ; n=6$ paired measures); see Figure 7 . HFF decreased by $7.3 \%$ points $(d=-1.27$; $p=.03 ; n=6$ paired measures; Figure 8 ). 


\section{Figure 7}

Treatment Differences in Ectopic Fat Depot Volumes

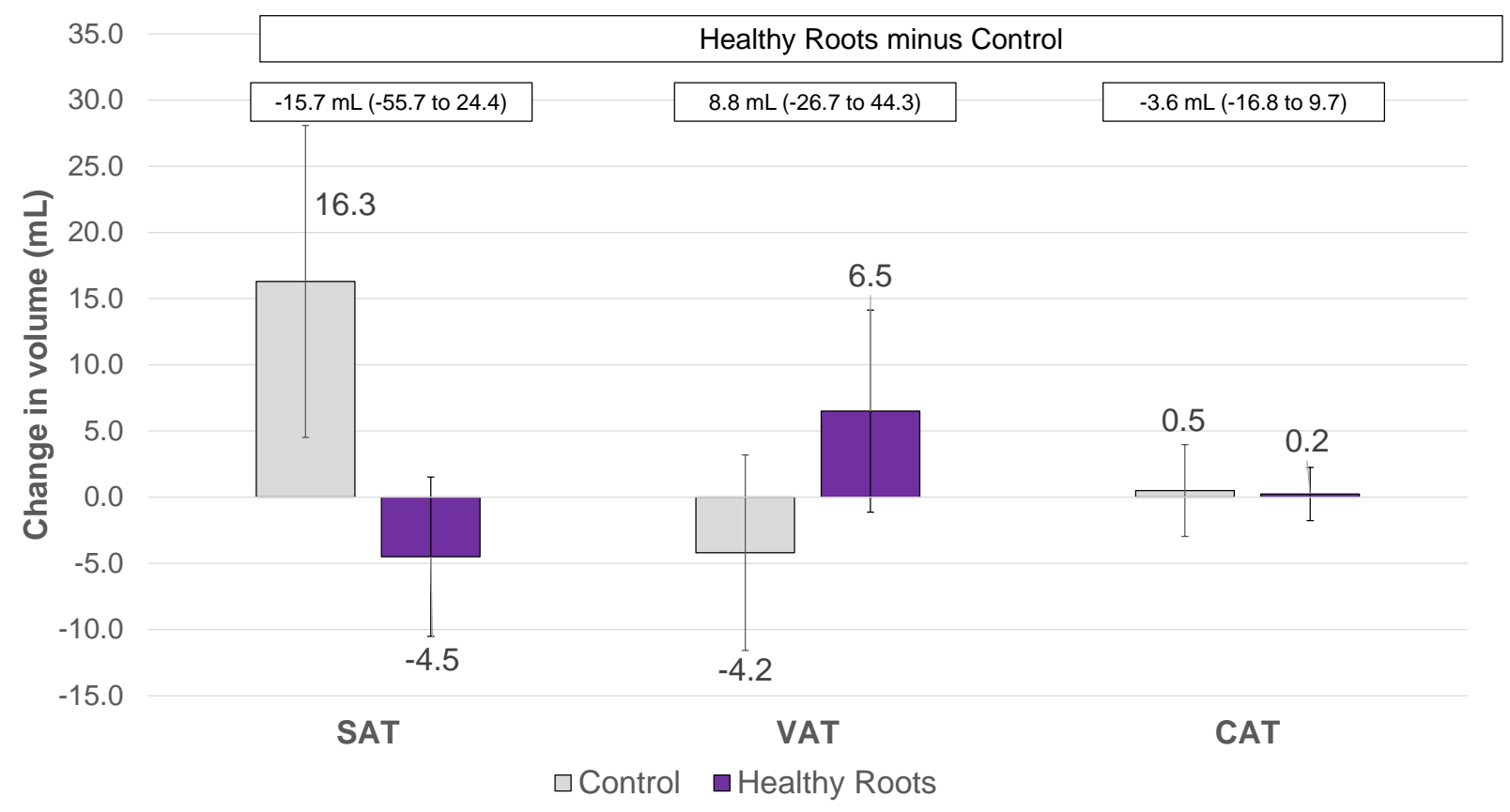

Note: The first value in the box is the mean difference (Healthy Roots minus Control). Values in parentheses are the upper and lower 95\% confidence limits of the mean difference. Bars display within-group changes. The mean difference may not precisely match the difference of the values displayed on the bars due to rounding, and because only 4 pairs of measures were used for the ttest for SAT, and 6 for VAT and CAT. The error bars represent standard errors. SAT $=$ subcutaneous adipose tissue; $\mathrm{VAT}=$ visceral adipose tissue $; \mathrm{CAT}=$ cardiac adipose tissue . 


\section{Figure 8}

Treatment Difference in the Hepatic Fat Fraction

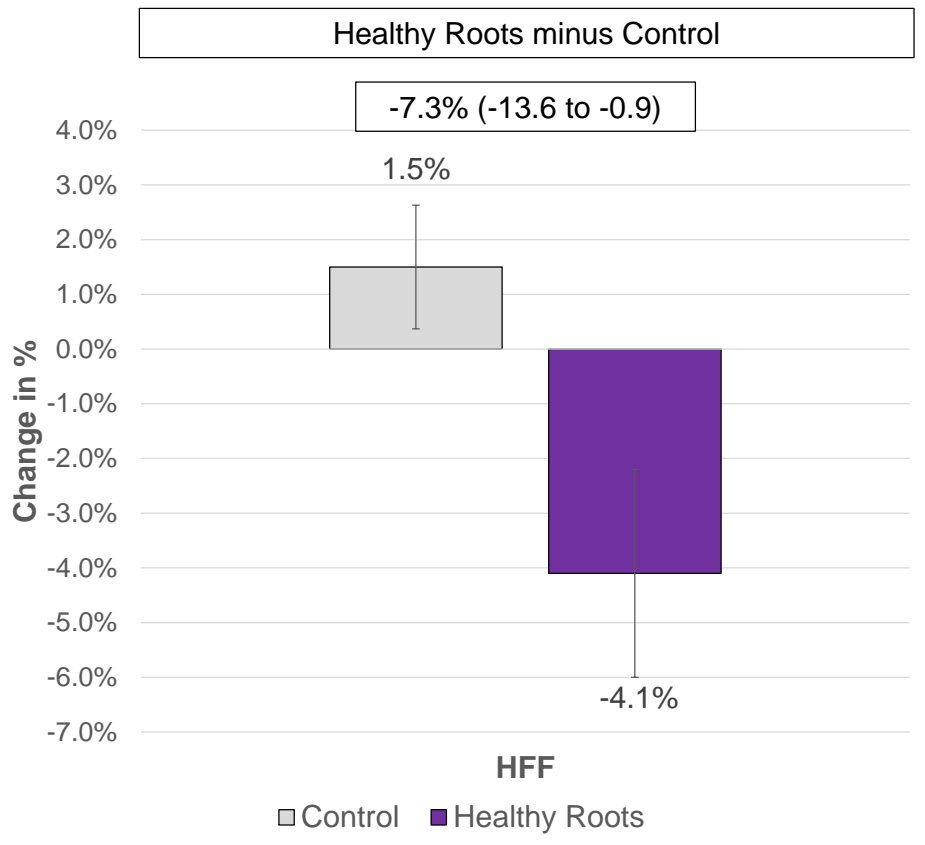

Note. The first value in the box is the mean difference (Healthy Roots minus Control). Values in parentheses are the upper and lower $95 \%$ confidence limits of the mean difference. Bars display within-group changes. The mean difference may not precisely match the difference of the values displayed on the bars due to rounding, and because only 6 pairs of measures were used for the ttest. The error bars represent standard errors. HFF $=$ hepatic fat fraction.

\section{Chronic Pain}

At the baseline visit, 9 out of the 21 participants (42.9\%) who completed the assessment reported chronic pain (rated at $M=4.6$ units out of 10, SD $=1.4$ ), and 8 of 18 participants (44.4\%) reported chronic pain at the end of the control period (rated at $M=4.0, S D=1.7$ ). Two participants who did not report chronic pain at the beginning of the control period had developed it by the end; and two participants who did report chronic pain at the beginning of the control period did not report it at the end $(p=.05)$. In those who reported chronic pain at both time points $(n=6)$, the mean pain score decreased by 1 unit out of $10(M=-1.0, S D=1.1$; $95 \% \mathrm{CI}$ : -2.1 to $0.2 ; p=.08)$. Four out of the 19 participants $(21.1 \%)$ who completed the assessment at the end of the intervention period reported chronic pain (rated at $M=4.3, S D=1.5$ ). None of the 10 participants who did not report chronic pain at the beginning of the intervention period had developed it by the end; and 5 participants of 8 who did report chronic pain at the beginning of the intervention did not report it at the end $(62.6 \%$ of those with chronic pain; $p=0.20)$. In those 
who reported chronic pain at both pre- and post-Healthy Roots visits $(n=3)$, the mean pain score did not decrease $(M=0.0, S D=2.0 ; 95 \%$ CI: -5.0 to $5.0 ; p=1.00)$; see Figure 9 .

\section{Figure 9}

Changes in Frequency and Severity of Self-Reported Chronic Pain
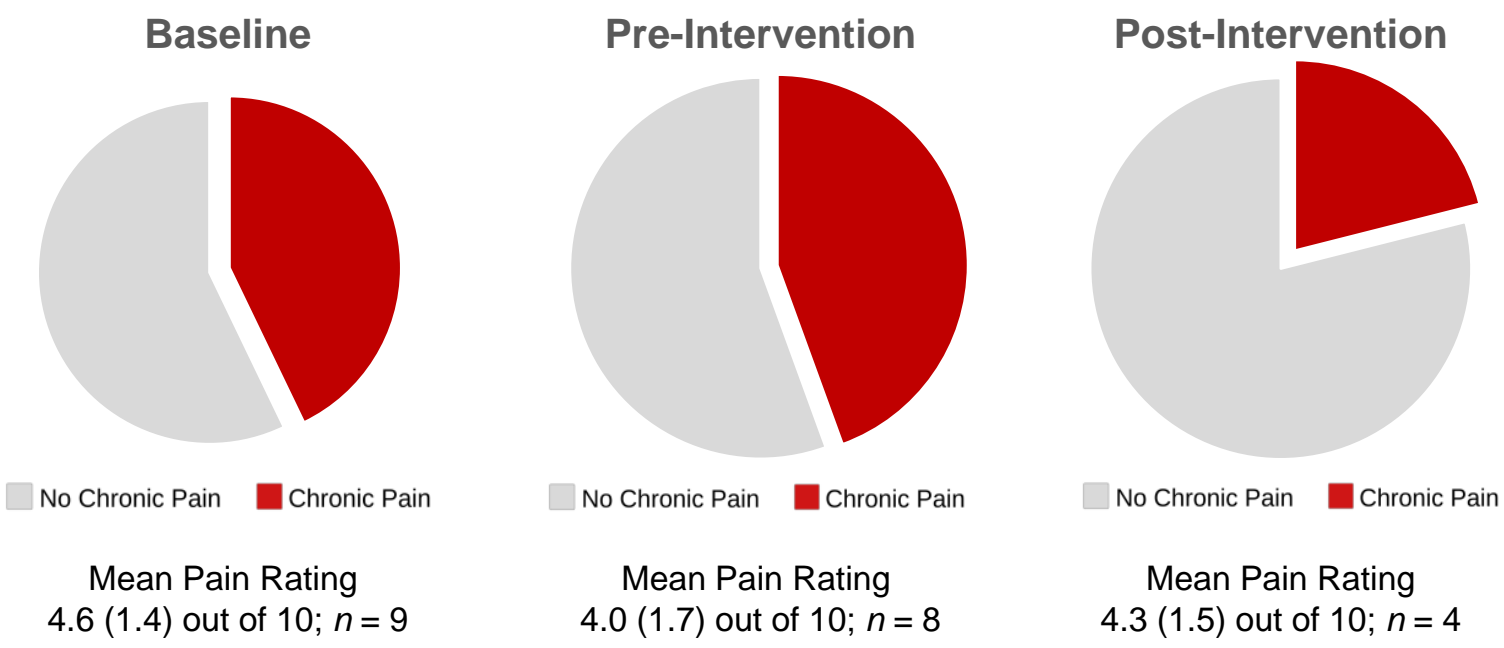

Note. Pie graphs show the proportion of the study sample who reported having chronic pain at each measurement occasion; numbers below each pie graph illustrate the mean pain rating (standard deviation) of those reporting chronic pain on each occasion.

\section{Mental Well-Being}

Participants completed a mental health and stress questionnaire at two visits: pre- and post-intervention. The mean PHQ-9 score pre-intervention was $6.2(S D=5.3)$, consistent with mild depressive symptoms. After the Healthy Roots intervention, it was $3.5(S D=5.4)$, consistent with minimal depression which may not require treatment $(d=-0.70 ; p=.07)$; see Figure 10. Overall, 8 out of 22 participants (36.4\%) reported feeling sad, "blue," or depressed for 2 weeks or more in a row during the 3 months prior to beginning the intervention; and 4 out of $19(21.1 \%)$ felt so after the intervention (difference $=-15.3 \% ; 95 \% \mathrm{CI}:-42.5$ to $12.0 ; p=.21$ ). Two participants who did not report feeling sad, "blue," or depressed for 2 weeks or more in a row during the 3 months prior to beginning Healthy Roots felt so after the intervention; and four participants who reported feeling sad, "blue," or depressed for 2 weeks or more in a row during the 3 months prior to Healthy Roots, did not feel so after the intervention $(p=0.56)$; see Figure 11 . 


\section{Figure 10}

PHQ-9 Scores Before and After the Intervention

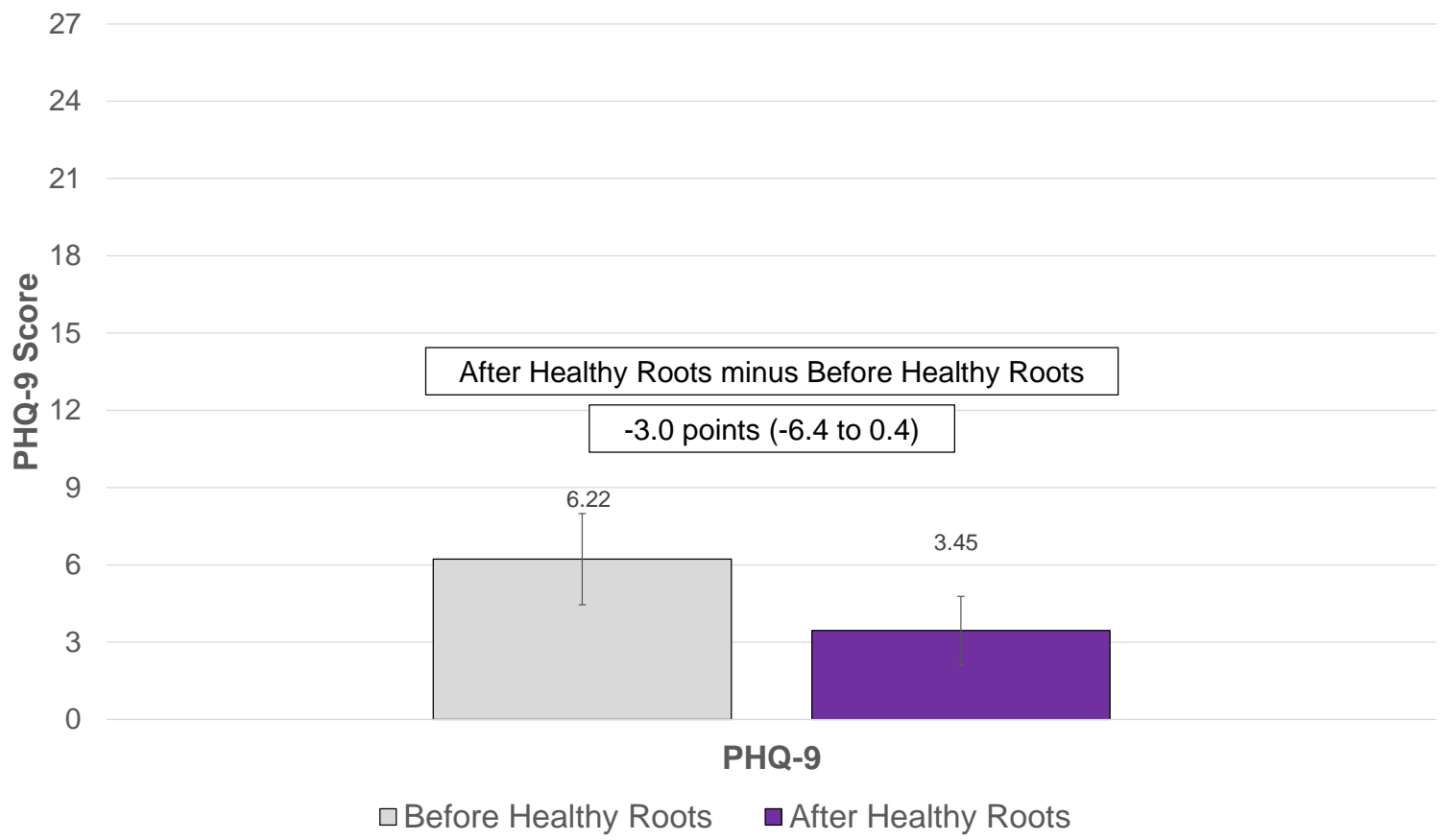

Note. The first value in the box is the mean difference (After Healthy Roots minus Before Healthy Roots). Values in parentheses are the upper and lower 95\% confidence limits of the mean difference. Bars display means PHQ-9 score at each time point. The mean difference may not precisely match the difference of the values displayed on the bars due to rounding, and because only 9 pairs of measures were used for the t-test. The error bars represent standard errors. PHQ-9 = Patient Health Questionnaire. 


\section{Figure 11}

Changes in Indicators of Self-Reported Mental Well-Being

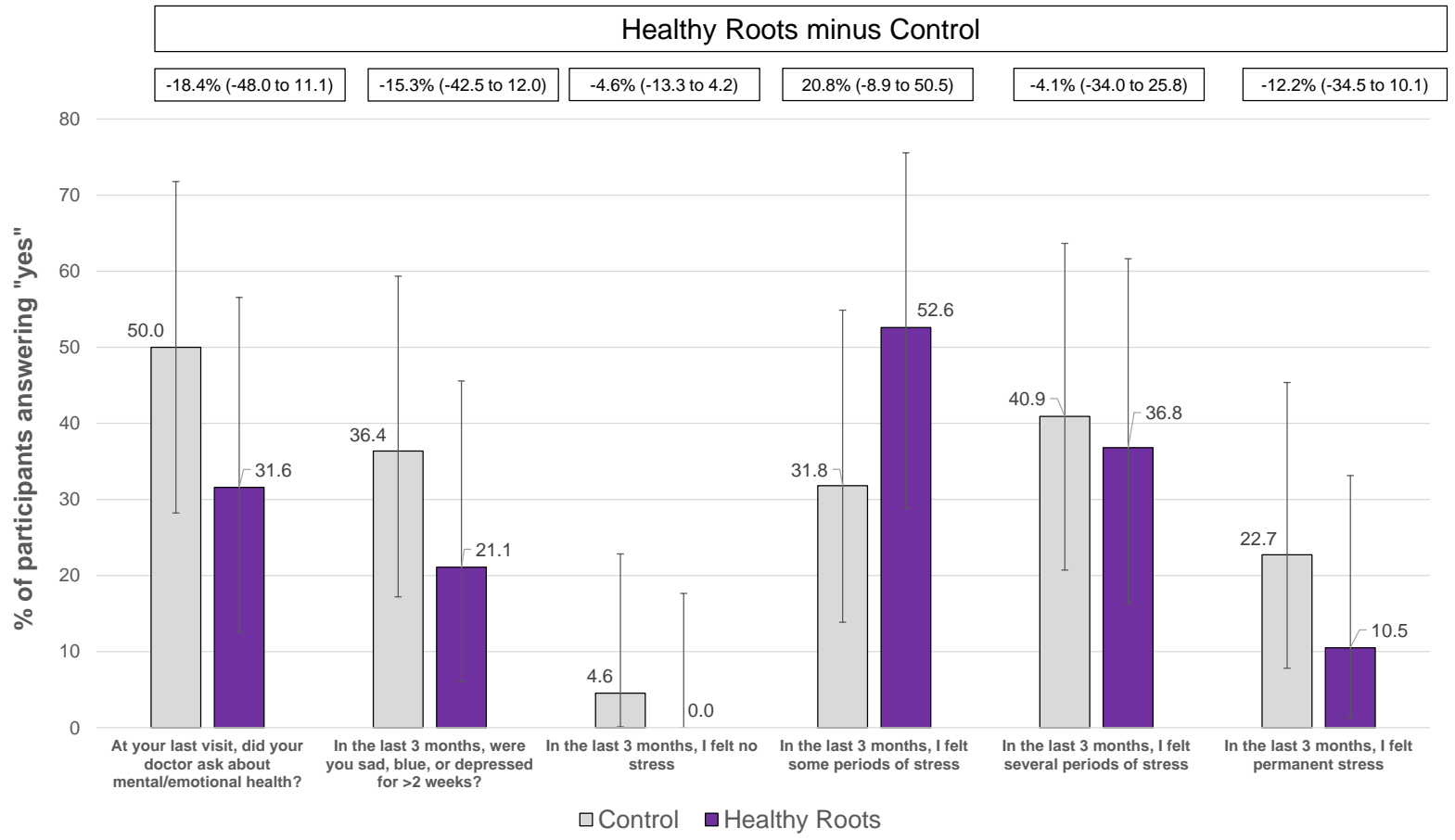

Note. The first value in the box is the mean difference (\%) (Healthy Roots minus Control). Values in parentheses are the upper and lower $95 \%$ confidence limits of the mean difference. Bars display within-group percentages. The mean difference may not precisely match the difference of the values displayed on the bars due to rounding. The error bars represent standard errors.

\section{Engagement}

Four engagement approaches were employed in the Healthy Roots intervention providing 13 opportunities for contact with participants: community events ( $n=4$ offerings); sharing circles ( $n=3$ offerings); one-on-one counselling sessions with a dietitian ( $n=3$ sessions); and healthy gardening/cooking workshops ( $n=3$ workshops). All participants attended at least one engagement opportunity ( $M d n=7$ sessions; interquartile range $=4)$. Participants attended a median of 2 community events, 2 sharing circles, 2 one-on-one intervention visits, and 2 healthy gardening/cooking workshops each. Overall engagement in the program, defined as number of engagement events attended, was not statistically associated with changes in weight, $r(15)=$ $-.33, p=.20$; waist circumference, $r(15)=-.43, p=.08$; HbA1c $r(15)=-.57, p=.11$; or HFF $r(15)=-.41 ; p=.36$ (Figure 12). However, this result is likely driven by the universally high engagement level of participants_-over $85 \%$ attended at least five events. 


\section{Figure 12}

Scatterplot of Changes in Weight (Top Left), Waist Circumference (Top Right), Hemoglobin Alc (Bottom Left), and Hepatic Fat Fraction (Bottom Right) against Engagement in Program
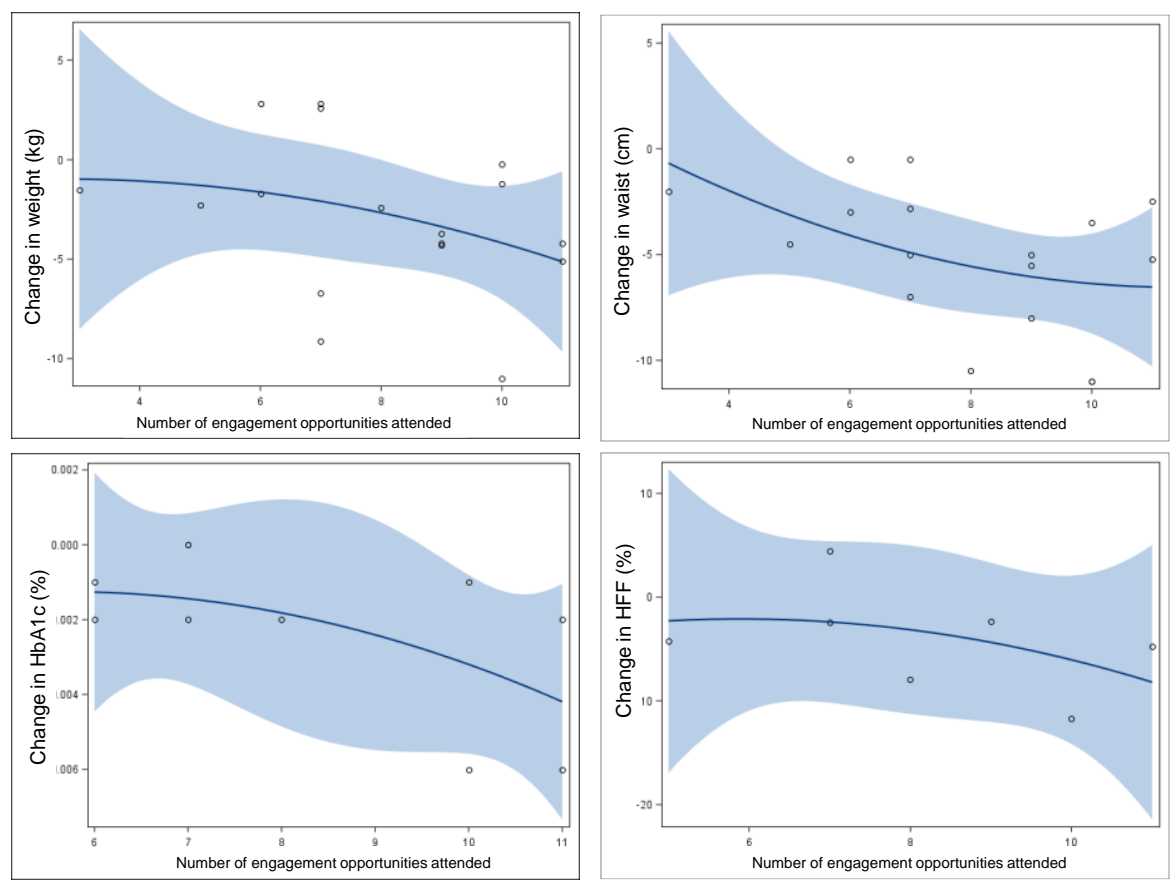

Note. Values in parentheses are $95 \%$ confidence intervals. HbA1c $=$ hemoglobin A1c; HFF $=$ hepatic fat fraction.

\section{Adherence}

By self-report, 95\% of participants always consumed foods from the "garden," 74\% always consumed foods from the "woods," 74\% always consumed foods from the "meadows," $37 \%$ always consumed foods from the "skies," and 32\% always consumed foods from the "water" (Figure 13). The figure features stacked bars, indicating the percentage of time respondents never, sometimes, and always ate foods from the category $(n=19)$. 


\section{Figure 13}

Summary of Responses to the Question "How Often Did You Eat Foods From the Woods, Skies, Garden, Meadow, and Water?"

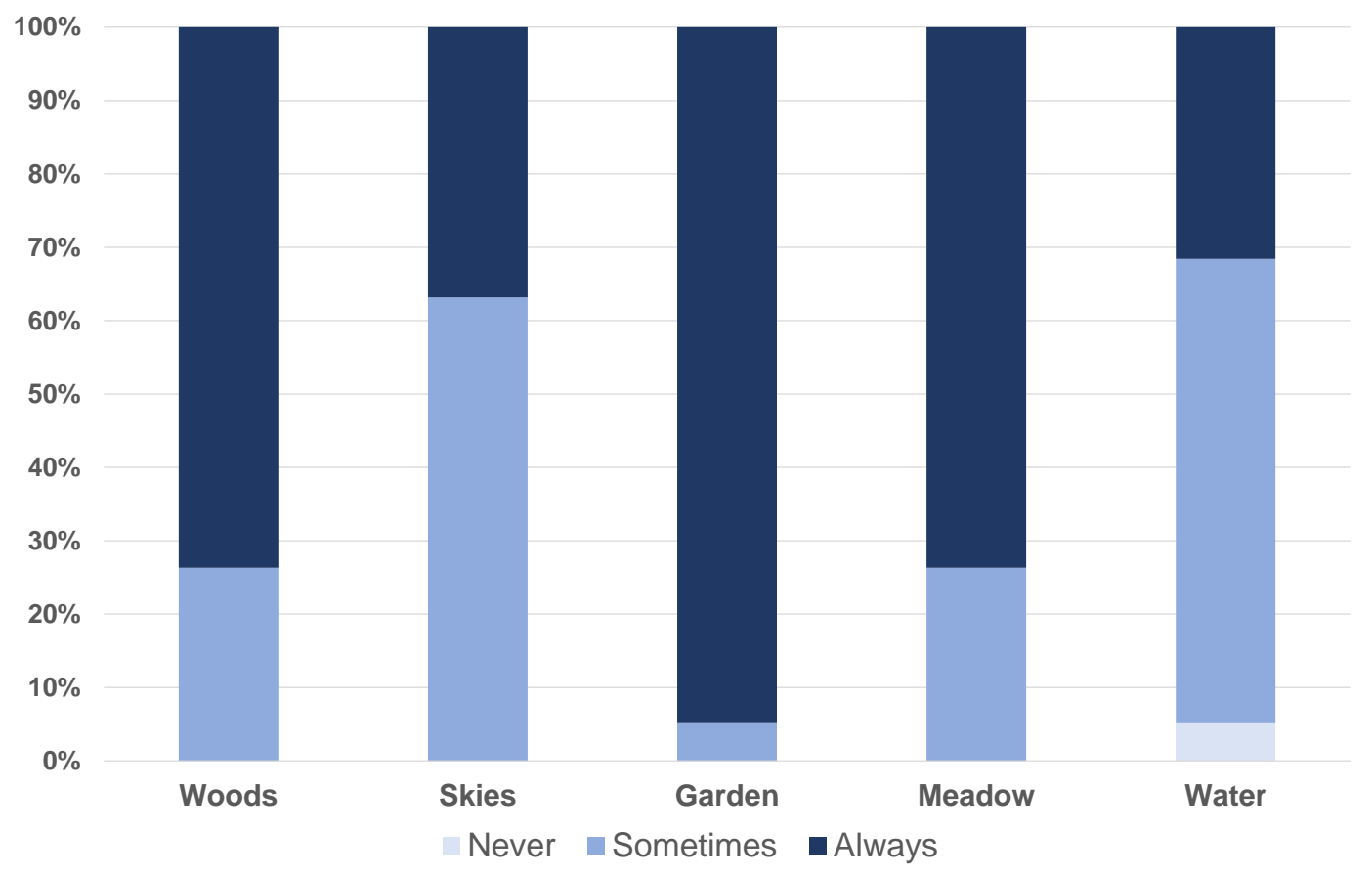

\section{Symptoms}

The transition from the control diet to the Healthy Roots diet resulted in no significant changes in self-reported satiety, bloating, or the palatability of the diet, but it did reduce selfreported gas. Three out of the 7 participants (43\%) who responded to these questions reported feeling less gassy than usual; $p<.001$ ). During both periods, diarrhea and constipation were rare, and there were no changes in frequency of bowel movements.

\section{Participant Feedback}

Seven participants consented to telling and sharing their stories at our end-of-study sharing circles, from which we produced a video (https://youtu.be/WVOki0zH154). Themes present in these stories included the following:

- an increased sense of cultural connectedness. "When I look back, this was as natural as what our ancestors ate a long time ago"; "I'm really grateful that I did the Healthy Roots. It's taught me a lot about who I am and every aspect of who I am."

- more awareness of the role of food in their lives. "It's not just about the food. It's physical, emotional, spiritual, mental wellness. And how food fits into all those 
areas"; "It's accelerated me spiritually which has affected me emotionally and physically, too."

- a change in food preferences. "[The difference between] being Healthy Roots hungry and being fast food hungry [is that] you're feeding your spirit as opposed to just, you know, binge eating."

- increased food literacy. "I learned how to incorporate more of our traditional foods into mainstream dishes"; "I'm cooking. I never have cooked in my life. I'm cooking all the time. Every day. I'm freezing food! I'm gardening. So I'm doing things that I've never done before and that I enjoy doing that help me balance."

- a desire for the lessons learned during the study to leave a legacy. "Everything that I learned throughout this entire session [...] I can adapt that to my everyday living with my children, and hopefully, they can carry it on with their families."

The experience also increased many participants' awareness of the food production process (e.g., "I want to know where this food is coming from. Who has been touching this food? How it's been grown before I kind of put it in my body.")

Difficulties with the program included incorporating unfamiliar foods (e.g., "The hardest part is being open to eating fish because [I've] not grown up with fish, except tuna.")

\section{Limitations}

Our study has some limitations. We did not build in a formal qualitative study that would have aided in the understanding of whether, and if so, how, the intervention improved measures of overall well-being and cultural connectedness. The primary intention of this study was to assess the physical impacts of the intervention. With respect to issues related to study execution, we note a few additional limitations. First, participants found it challenging to adhere to the diet. Our mitigation strategy was to provide a bimonthly food box; however, it is likely that without food provision, engagement and adherence would be lower. Second, although some food was provided, we were not able to mimic a "metabolic feeding" study and some nontraditional foods may have offset the potential benefits of the dietary protocol. Third, because of our requirements for the MRI scans, our study systematically excluded certain groups of interested participants, specifically men with a high body mass index, who could not fit in the St. Joseph's Health Centre research MRI machine. Fourth, most participants were female. Finally, we were only able to collect repeat blood samples and MRI data from a subset of the 22 enrolled participants during the baseline observation: 13 people (62\%) provided repeat blood samples; 7 provided repeat MRI scans (33\%). This was because of scheduling conflicts, participant refusal to provide samples, and an inability of some participants to complete the MRI scan due to coughing or claustrophobia. Finally, a limitation of this pre-post study is that we could not control other unmeasured factors that also changed at the same time as the intervention was implemented. Therefore, changes in outcomes during the Healthy Roots period cannot be fully attributed to the intervention.

V OLUME 16 , IS S UE 2, $2021 \bullet 105$ 


\section{Discussion}

In this study, the intervention facilitated a return to a traditional Haudenosaunee diet, which has great cultural significance for the Haudenosaunee, who are strongly connected to food and land. Participant engagement in the program was high, and there was abundant support throughout the community. The results showed significant reductions in body weight, waist circumference, and improvements in HFF and HbA1c.

The major biochemical change observed was a significant reduction in HbA1c. Higher protein, lower refined-carbohydrate diets result in significant weight loss and HbA1c reductions in high-risk populations. The magnitude of HbAlc change after 3 months' intervention in our study $(-0.2 \%$ points) was smaller, but directionally consistent with that reported in a systematic review and meta-analysis of high-protein diets in type 2 diabetes $(-0.5 \%$ units; Dong et al., 2013). A diet higher in polyunsaturated fat content through nuts and seeds has been shown to reduce $\mathrm{HbA1c}$ in populations with diabetes (Parham et al., 2014; Viguiliouk et al., 2014). A meta-analysis of 102 randomized trials showed that replacing saturated fat with polyunsaturated fat significantly lowers glucose, $\mathrm{HbA1c}, \mathrm{C}$-peptide, and markers of insulin resistance (Imamura et al., 2016). In trials that used gold-standard acute insulin response, polyunsaturated fat significantly improved insulin secretion capacity, whether it replaced carbohydrate, saturated fat, or monounsaturated fat (Imamura et al., 2016).

The Healthy Roots diet did not change Apo-A1 relative to control, but it did increase Apo-B and the Apo-B:Apo-A1 ratio, despite significant reductions in waist circumference, body weight, and HbA1c. The effect was not altered when we removed two participants with extreme change in these lipids. In a study of 19 men with metabolic syndrome, a $9 \%$ reduction in body weight was associated with a reduced Apo-A1 catabolic rate $(-8 \%)$ but no change in its production (2\%; Richard et al., 2013); thus, we would have expected Apo-A1 concentrations to rise or remain the same. In our study, change in weight was not associated with changes in Apo$\mathrm{A} 1(r[7]=.16, p=.68)$, or waist circumference $(r[7]=-.39, p=.30)$.

The change in dietary composition that accompanied the diet would be expected to reduce Apo-B:A1, but we did not see that. Total and monounsaturated fat intake were unchanged according to self-report, but saturated fat decreased by $4 \%(95 \% \mathrm{CI}:-6$ to -2$)$ of energy, polyunsaturated fat increased by $4 \%$ (95\% CI: 2 to 6$)$ of energy, so the polyunsaturated to saturated fat (P:S) ratio increased by 0.9 units (95\% CI: 0.5 to 1.3$)$. Protein also increased on Healthy Roots by 5.1\% (95\% CI: 1.3 to 8.9), and carbohydrate decreased by $4.7 \%$ (95\% CI: -10.0 to 0.5 ). These changes should favour a reduction in Apo-B (Furtado et al., 2008). However, a higher ratio of P:S fatty acids (largely achieved by increasing n-6) reduces Apo-A1 (Lee et al., 2012) and alters the chemical composition, thermotropic properties, and subfraction distribution of HDL-C. Whether this change alters the fractional rate of catabolism of Apo A-1 is uncertain (Brousseau et al., 1995; Shepherd et al., 1978). Some studies have found that fish oil supplements, or diets rich in oily fish may slightly raise LDL-cholesterol, which would reflect in Apo-B (Fumeron et al., 1991; Rajaram et al., 2009).

The two major sources of polyunsaturated fats in the Haudenosaunee diet were sunflower oil and walnuts (supplying $\approx 20 \%-40 \%$ of a typical participant's polyunsaturates). Other nuts

V OLUME 16 , IS S UE 2, $2021 \cdot 106$ 
and seeds (peanuts, almonds, brazil nuts, pumpkin seeds, and pecans), meats (salmon, duck, turkey), and salad dressings provided the remainder. Sunflowers have been cultivated by Haudenosaunee for centuries and have significant status in Haudenosaunee culture as one of the original plants given to us by the Creator (Hart \& Lovis, 2013; Mt. Pleasant, 2016). Sunflower oil contains a high ratio of n-6 linoleic to $n-3$ linolenic acid (>100:1) while walnuts have a lower ratio (4:1). Most other plant and animal sources in the Haudenosaunee Food Guide fall between this range, except for salmon (0.7:1). Few trials have directly tested the influence of the n-6:n-3 ratio on serum lipids when polyunsaturated fat replaces saturated fat. In one trial in type 2 diabetes (Müllner et al., 2014), diets both high and low in the n-6:n-3 ratio resulted in similar changes in the lipid profile when polyunsaturated fat replaced saturated fat. In one trial in hypercholesterolemic men, a low saturated fat diet with a high n-3:n-6 ratio reduced Apo-A1 (Sanders et al., 1997). Omega-3 $\alpha$-linolenic acid (of which walnuts are a major source) may reduce the risk of coronary artery disease (Pan et al., 2012), but evidence from clinical trials that have attempted to isolate the influence of $\alpha$-linolenic acid is limited (Kromhout et al., 2010).

Few studies have tested the metabolic effects of a return to ancestral eating patterns in Indigenous communities. A study of 10 Indigenous Australians with type 2 diabetes from the Mowanjum Community in the northern Kimberley region (Derby, Western Australia) were tested before and after living for 7 weeks as "hunter-gatherers" (O'Dea, 1984). The diet was mixed and included locally killed meat (beef, kangaroo), freshwater fish and turtle, vegetables, and honey. The macronutrient profile of this diet was very high in protein (54\%), low in fat (13\%), and low in carbohydrate (33\%). Animal foods accounted for up to 64\% of energy. After 7 weeks, glucose tolerance, insulin response to glucose, and lipids were greatly improved. In a female Mexican population, those who followed a traditional Mexican diet had 23\% lower serum hsCRP (a marker of systemic inflammation; $p<.05)$ and $15 \%$ lower insulin concentrations $(p<$ .05; Santiago-Torres et al., 2015).

The Healthy Roots diet reduced the absolute HFF by $7.3 \%$ points (95\% CI: 0.9 to $13.6 ; p$ $=.04)$, which is a relative reduction of $85 \%(95 \% \mathrm{CI}:-163$ to $-9 ; p=.03)$. In a 2-year parallel study in 165 overweight and obese men and women, hepatic fat reduction was more strongly associated with weight loss than with a specific dietary profile (de Souza et al., 2012). However, in a 6-week crossover trial of 12 individuals with nonalcoholic fatty liver, a Mediterranean diet improved insulin sensitivity and reduced liver steatosis without weight reduction (Ryan et al., 2013). Thus, weight change and diet quality may affect hepatic fat through independent but complementary mechanisms. In a 2-year diet trial involving 70 obese postmenopausal women, a Paleolithic diet reduced liver fat by $64 \%$ after 6 months and $50 \%$ after 2 years; a conventional low-fat diet reduced liver fat by $43 \%$ after 6 months and $49 \%$ after 2 years (Otten et al., 2016). Participants in this study increased n-3 polyunsaturated fat intake during the intervention, and a recent meta-analysis found that n-3 supplements lowered hepatic fat (Parker et al., 2012). Thus, several outcomes of the program (e.g., weight loss, lower carbohydrate, higher protein and fat, and higher omega-3 fat intake) likely contributed to the observed reduction in HFF. This finding is important because increased hepatic fat is associated with the development of atherosclerosis 
and cardiovascular events, type 2 diabetes, and other vascular disease (Allen et al., 2018; Stefan et al., 2008; Williams et al., 2013).

Pre-intervention, eight participants reported depressive symptoms. The mean PHQ-9 score change from pre-intervention to the end of intervention was -3.0 points $(95 \% \mathrm{CI}:-6.4$ to $0.4 ; p=.073)$. Although the result was statistically nonsignificant, the reduction in depressive feelings is promising since the Haudenosaunee Food Guide is rich with foods high in folate, iron, long-chain omega-3 fatty acids, magnesium, potassium, selenium, thiamine, vitamin A, vitamin $\mathrm{B}_{6}$, vitamin $\mathrm{B}_{12}$, vitamin $\mathrm{C}$, and zinc, including oyster, clam, fish, organ meats, pumpkin, squash, and strawberry. These nutrients are believed to have mood-enhancing properties (LaChance \& Ramsey, 2018).

The participants who provided in-depth interviews about their study experiences suggested that the Healthy Roots intervention had a positive impact on their relationship with food and on their self-perceived health, and it fostered a sense of connection with their ancestral roots and ways of life. We would like to pursue future formal qualitative studies that explore these sentiments more rigorously.

The strengths of our study included, first, high adherence to the dietary principles and engagement in the program, as indicated by participant feedback and 3-day diet records_-almost half of the participants intended to continue following a traditional Haudenosaunee diet after the study had completed. Second, we were able to collect blood and urine specimens from nearly all participants for the analysis of change in risk factors and future genetic analyses. Third, we collected dietary data both pre- and post-intervention.

\section{Conclusion}

In this paper, we have presented the results of an Indigenous-initiated partnership with an academic institution to evaluate the effect of a return to a traditional diet on cardiovascular risk factors. By capitalizing on the momentum of earlier community engagement, this project increased awareness and served as a catalyst for change in the community through a shared process and partnership with allies. We have shown that a return to a traditional Haudenosaunee diet is associated with favourable changes in body weight, body mass index, waist circumference, HbA1c, and the hepatic fat fraction. This cultural mechanism for maintaining and honouring our relationship to land and food is sustainable. The results confirm what Haudenosaunee have always known, that our food is more than just sustenance, it is our medicine. Returning to a traditional diet would likely make people feel healthier physically and mentally, since restoring our traditional foodways and connection to our foods could increase cultural connectedness. Anecdotal community reports indicate that the number of people taking up gardening in the months following the Healthy Roots challenges and study were growing. We hope the results described in this manuscript provide enhanced motivation for continued progress toward food sovereignty. Traditional food and foodways foster a sense of connection to the community, the past, and the land for many Indigenous Peoples (Kant et al., 2015; Pufall et al., 2011; Samson \& Pretty, 2006; Willows, 2005). They are also ways of restoring and maintaining 
traditional knowledge about food and the land that is being lost. In Haudenosaunee culture, there is no distinction between food and medicine, because food is our medicine-just as the roots connect the plants, our sustenance connects us to our identity.

\section{References}

Adelson, N. (2005). The embodiment of inequity: Health disparities in Aboriginal Canada. Canadian Journal of Public Health, 96, S45-S61. https://doi.org/10.1007/BF03403702

Allen, A. M., Therneau, T. M., Larson, J. J., Coward, A., Somers, V. K., \& Kamath, P. S. (2018). Nonalcoholic fatty liver disease incidence and impact on metabolic burden and death: A 20 year-community study. Hepatology, 67(5), 1726-1736. https://doi.org/10.1002/hep.29546

Anand, S. S., Abonyi, S., Arbour, L., Balasubramanian, K., Brook, J., Castleden, H., Chrisjohn, V., Cornelius, I., Davis, A. D., Desai, D., de Souza, R. J., Friedrich, M. G., Harris, S., Irvine, J., L’Hommecourt, J., Littlechild, R., Mayotte, L., McIntosh, S., Morrison, J., ... on behalf of the Canadian Alliance for Healthy Hearts and Minds First Nations Research Group. (2019). Explaining the variability in cardiovascular risk factors among First Nations communities in Canada: A population-based study. The Lancet Planetary Health, 3(12), E511-E520. https://doi.org/10.1016/S2542-5196(19)30237-2

Anand, S. S., Tu, J. V., Awadalla, P., Black, S., Boileau, C., Busseuil, D., Desai, D., Després, J.-P., de Souza, R. J., Dummer, T., Jacquemont, S., Knoppers, B., Larose, E., Lear, S. A., Marcotte, F., Moody, A. R., Parker, L., Poirier, P., Robson, P. J. ... on behalf of the CAHHM Study Investigators. (2016). Rationale, design, and methods for Canadian Alliance for Healthy Hearts and Minds cohort study (CAHHM) - A pan Canadian cohort study. BMC Public Health, 16(1), Article 650. https://doi.org/10.1186/s12889-016-33108

Anand, S. S., Yusuf, S., Vuksan, V., Devanesen, S., Teo, K. K., Montague, P. A., Kelemen, L., Yi, C., Lonn, E., Gerstein, H., Hegele, R. A., \& McQueen, M. (2000). Differences in risk factors, atherosclerosis, and cardiovascular disease between ethnic groups in Canada: The Study of Health Assessment and Risk in Ethnic groups (SHARE). The Lancet, 356(9226), 279-284. https://doi.org/10.1016/s0140-6736(00)02502-2

Anand, S. S., Yusuf, S., Jacobs, R., Davis, A. D., Yi, Q., Gerstein, H., Montague, P. A., \& Lonn, E. (2001). Risk factors, atherosclerosis, and cardiovascular disease among Aboriginal people in Canada: the Study of Health Assessment and Risk Evaluation in Aboriginal Peoples (SHARE-AP). Lancet (London, England), 358(9288), 1147-1153. https://doi.org/10.1016/s0140-6736(01)06255-9

Brousseau, M. E., Schaefer, E. J., Stucchi, A. F., Osada, J., Vespa, D. B., Ordovas, J. M., \& Nicolosi, R. J. (1995). Diets enriched in unsaturated fatty acids enhance apolipoprotein A-I catabolism but do not affect either its production or hepatic mRNA abundance in cynomolgus monkeys. Atherosclerosis, 115(1), 107-119. https://doi.org/10.1016/00219150(94)05505-D

Cohen, J. (1988). Statistical Power Analysis for the Behavioral Sciences (2nd ed.). Hillsdale, NJ: Lawrence Erlbaum Associates, Publishers. 
DeCaire, R. (2012). Understanding Indigenous agricultural systems. Heritage Matters, 10(3), 45. https://www.yumpu.com/en/document/read/22252197/heritage-matters-back-to-theland-october-2012

de Souza, R. J., Bray, G. A., Carey, V. J., Hall, K. D., LeBoff, M. S., Loria, C. M., Laranja, N. M., Sacks, F. M., \& Smith, S. R. (2012). Effects of 4 weight-loss diets differing in fat, protein, and carbohydrate on fat mass, lean mass, visceral adipose tissue, and hepatic fat: Results from the POUNDS LOST trial. American Journal of Clinical Nutrition, 95(3), 614-625. https://doi.org/10.3945/ajcn.111.026328

Dong, J.-Y., Zhang, Z.-L., Wang, P.-Y., \& Qin, L.-Q. (2013). Effects of high-protein diets on body weight, glycaemic control, blood lipids and blood pressure in type 2 diabetes: Metaanalysis of randomised controlled trials. British Journal of Nutrition, 110(5), 781-789. https://doi.org/10.1017/S0007114513002055

First Nations Information Governance Centre. (2018). National report of the First Nations Regional Health Survey Phase 3: Volume 2. https://fnigc.ca/wpcontent/uploads/2020/09/53b9881f96fc02e9352f7cc8b0914d7a_FNIGC_RHS-Phase-3Volume-Two_EN_FINAL_Screen.pdf

Fumeron, F., Brigant, L., Ollivier, V., de Prost, D., Driss, F., Darcet, P., Bard, J. M., Parra, H. J., Fruchart, J. C., \& Apfelbaum, M. (1991). n-3 polyunsaturated fatty acids raise lowdensity lipoproteins, high-density lipoprotein 2, and plasminogen-activator inhibitor in healthy young men. The American journal of clinical nutrition, 54(1), 118-122. https://doi.org/10.1093/ajcn/54.1.118

Furtado, J. D., Campos, H., Appel, L. J., Miller, E. R., Laranjo, N., Carey, V. J., \& Sacks, F. M. (2008). Effect of protein, unsaturated fat, and carbohydrate intakes on plasma apolipoprotein B and VLDL and LDL containing apolipoprotein C-III: results from the OmniHeart Trial. The American journal of clinical nutrition, 87(6), 1623-1630. https://doi.org/10.1093/ajcn/87.6.1623

Gionet, L., \& Roshanafshar, S. (2013). Select health indicators of First Nations people living off reserve, Métis and Inuit. Statistics Canada, Catalogue No. 82-624-X. https://www150.statcan.gc.ca/n1/pub/82-624-X/2013001/article/11763-eng.htm

Gordon, K., Lickers Xavier, A., \& Neufeld, H. T. (2018). Healthy Roots: Building capacity through shared stories rooted in Haudenosaunee knowledge to promote Indigenous foodways and well-being. Canadian Food Studies, 5(2), 180-195. https://doi.org/10.15353/cfs-rcea.v5i2.210

Hart, J. P., \& Lovis, W. A. (2013). Reevaluating what we know about the histories of maize in northeastern North America: A review of current evidence. Journal of Archaeological Research, 21, 175-216. https://doi.org/10.1007/s10814-012-9062-9

Imamura, F., Micha, R., Wu, J. H. Y., de Oliveira Otto, M. C., Otite, F. O., Abioye, A. I., \& Mozaffarian, D. (2016). Effects of saturated fat, polyunsaturated fat, monounsaturated fat, and carbohydrate on glucose-insulin homeostasis: A systematic review and metaanalysis of randomised controlled feeding trials. PLoS Medicine, 13(7), Article e1002087. https://doi.org/10.1371/journal.pmed.1002087 
Kant, J. M., Larson, G. E., Burckhard, S. R., Berdanier, B. W., \& Meyers, R. T. (2015). Contemporary use of wild fruits by the Lakota in South Dakota and implications for cultural identity. Great Plains Research, 25(1), 13-24. https://doi.org/10.1353/gpr.2015.0011

Kroenke, K., Spitzer, R. L., \& Williams, J. B. W. (2001). The PHQ-9: Validity of a brief depression severity measure. Journal of General Internal Medicine, 16(9), 606-613. https://doi.org/10.1046/j.1525-1497.2001.016009606.x

Kromhout, D., Giltay, E. J., \& Geleijnse, J. M. (2010). n-3 fatty acids and cardiovascular events after myocardial infarction. New England Journal of Medicine, 363(21), 2015-2026. https://doi.org/10.1056/NEJMoa1003603

Kwon, Y.-I., Apostolidis, E., Kim, Y.-C., \& Shetty, K. (2007). Health benefits of traditional corn, beans, and pumpkin: In vitro studies for hyperglycemia and hypertension management. Journal of Medicinal Food, 10(2), 266-275. https://doi.org/10.1089/jmf.2006.234

LaChance, L. R., \& Ramsey, D. (2018). Antidepressant foods: An evidence-based nutrient profiling system for depression. World Journal of Psychiatry, 8(3), 97-104. https://doi.org/10.5498/wjp.v8.i3.97

Lear, S. A., Humphries, K. H., Kohli, S., Frohlich, J. J., Birmingham, C. L., \& Mancini, G. B. J. (2007). Visceral adipose tissue, a potential risk factor for carotid atherosclerosis: Results of the Multicultural Community Health Assessment Trial (M-CHAT). Stroke, 38(9), 2422-2429. https://doi.org/10.1161/STROKEAHA.107.484113

Lee, S. P. S., Dart, A. M., Walker, K. Z., O’Dea, K., Chin-Dusting, J. P. F., \& Skilton, M. R. (2012). Effect of altering dietary n-6:n-3 PUFA ratio on cardiovascular risk measures in patients treated with statins: A pilot study. British Journal of Nutrition, 108(7), 12801285. https://doi.org/10.1017/S0007114511006519

Lewandowski, S. (1987). Diohe'ko, the three sisters in Seneca life: Implications for a Native agriculture in the Finger Lakes region of New York State. Agriculture and Human Values, 4, 76-93. https://doi.org/10.1007/BF01530644

McGorrian, C., Yusuf, S., Islam, S., Jung, H., Rangarajan, S., Avezum, A., Prabhakaran, D., Almahmeed, W., Rumboldt, Z., Budaj, A., Dans, A. L., Gerstein, H. C., Teo, K., Anand, S. S., \& on behalf of the INTERHEART Investigators. (2011). Estimating modifiable coronary heart disease risk in multiple regions of the world: The INTERHEART Modifiable Risk Score. European Heart Journal, 32(5), 581-589. https://doi.org/10.1093/eurheartj/ehq448

Mt. Pleasant, J. (2006). The science behind the three sisters mound system: An agronomic assessment of an Indigenous agricultural system in the Northeast. In J. E. Staller, R. H. Tykot, \& B. F. Benz (Eds.), Histories of maize in Mesoamerica: Multidisciplinary approaches (pp. 529-537). Academic Press. https://doi.org/10.1016/B978-0123693648/50290-4

Mt. Pleasant, J. (2011). The paradox of plows and productivity: An agronomic comparison of cereal grain production under Iroquois hoe culture and European plow culture in the 
seventeenth and eighteenth centuries. Agricultural History, 85(4), 460-492. https://doi.org/10.3098/ah.2011.85.4.460

Mt. Pleasant, J. (2016). Food yields and nutrient analyses of the three sisters: A Haudenosaunee cropping system. Ethnobiology Letters, 7(1), 87-98. https://doi.org/10.14237/ebl.7.1.2016.721

Mt. Pleasant, J., \& Burt, R. F. (2010). Estimating productivity of traditional Iroquoian cropping systems from field experiments and historical literature. Journal of Ethnobiology, 30(1), 52-79. https://doi.org/10.2993/0278-0771-30.1.52

Müllner, E., Plasser, E., Brath, H., Waldschütz, W., Forster, E., Kundi, M., \& Wagner, K.-H. (2014). Impact of polyunsaturated vegetable oils on adiponectin levels, glycaemia and blood lipids in individuals with type 2 diabetes: A randomised, double-blind intervention study. Journal of Human Nutrition and Dietetics, 27(5), 468-478. https://doi.org/10.1111/jhn.12168

O’Dea, K. (1984). Marked improvement in carbohydrate and lipid metabolism in diabetic Australian Aborigines after temporary reversion to traditional lifestyle. Diabetes, 33(6), 596-603. https://doi.org/10.2337/diab.33.6.596

Otten, J., Melberg, C., Ryberg, M., Sandberg, S., Kullberg, J., Lindahl, B., Larsson, C., Hauksson, J., \& Olsson, T. (2016). Strong and persistent effect on liver fat with a Paleolithic diet during a two-year intervention. International Journal of Obesity, 40, 747753. https://doi.org/10.1038/ijo.2016.4

Pan, A., Chen, M., Chowdhury, R., Wu, J. H. Y., Sun, Q., Campos, H., Mozaffarian, D., \& Hu, F. B. (2012). $\alpha$-Linolenic acid and risk of cardiovascular disease: A systematic review and meta-analysis. American Journal of Clinical Nutrition, 96(6), 1262-1273. https://doi.org/10.3945/ajen.112.044040

Parham, M., Heidari, S., Khorramirad, A., Hozoori, M., Hosseinzadeh, F., Bakhtyari, L., \& Vafaeimanesh, J. (2014). Effects of pistachio nut supplementation on blood glucose in patients with type 2 diabetes: A randomized crossover trial. The Review of Diabetic Studies, 11(2), 190-196. https://doi.org/10.1900/RDS.2014.11.190

Park, J., Tjepkema, M., Goedhuis, N., \& Pennock, J. (2015). Avoidable mortality among First Nations adults in Canada: A cohort analysis. Health Reports, 26(8), 10-16. https://www150.statcan.gc.ca/n1/en/pub/82-003-x/2015008/article/14216eng.pdf?st=y4fCmLjO

Parker, H. M., Johnson, N. A., Burdon, C. A., Cohn, J. S., O’Connor, H. T., \& George, J. (2012). Omega-3 supplementation and non-alcoholic fatty liver disease: A systematic review and meta-analysis. Journal of Hepatology, 56(4), 944-951. https://doi.org/10.1016/j.jhep.2011.08.018

Patchell, B., \& Edwards, K. (2014). The role of traditional foods in diabetes prevention and management among Native Americans. Current Nutrition Reports, 3, 340-344. https://doi.org/10.1007/s13668-014-0102-6

Pufall, E. L., Jones, A. Q., McEwen, S. A., Lyall, C., Peregrine, A. S., \& Edge, V. L. (2011). Perception of the importance of traditional country foods to the physical, mental, and 
spiritual health of Labrador Inuit. Arctic, 64(2), 242-250.

https://doi.org/10.14430/arctic4103

Rajaram, S., Haddad, E. H., Mejia, A., \& Sabaté, J. (2009). Walnuts and fatty fish influence different serum lipid fractions in normal to mildly hyperlipidemic individuals: a randomized controlled study. The American journal of clinical nutrition, 89(5), 1657S1663S. https://doi.org/10.3945/ajen.2009.26736S

Reading, J. (2015). Confronting the growing crisis of cardiovascular disease and heart health among Aboriginal Peoples in Canada. Canadian Journal of Cardiology, 31(9), 10771080. https://doi.org/10.1016/j.cjca.2015.06.012

Richard, C., Couture, P., Desroches, S., Lichtenstein, A. H., \& Lamarche, B. (2013). Effect of weight loss, independent of change in diet composition, on apolipoprotein AI kinetic in men with metabolic syndrome. Journal of Lipid Research, 54, 232-237. https://doi.org/10.1194/jlr.M029934

Ryan, M. C., Itsiopoulos, C., Thodis, T., Ward, G., Trost, N., Hofferberth, S., O’Dea, K., Desmond, P. V., Johnson, N. A., \& Wilson, A. M. (2013). The Mediterranean diet improves hepatic steatosis and insulin sensitivity in individuals with non-alcoholic fatty liver disease. Journal of Hepatology, 59(1), 138-143. https://doi.org/10.1016/j.jhep.2013.02.012

Samson, C., \& Pretty, J. (2006). Environmental and health benefits of hunting lifestyles and diets for the Innu of Labrador. Food Policy, 31(6), 528-553. https://doi.org/10.1016/j.foodpol.2006.02.001

Sanders, T. A. B., Oakley, F. R., Miller, G. J., Mitropoulos, K. A., Crook, D., \& Oliver, M. F. (1997). Influence of $n-6$ versus $n-3$ polyunsaturated fatty acids in diets low in saturated fatty acids on plasma lipoproteins and hemostatic factors. Arteriosclerosis, Thrombosis, and Vascular Biology, 17(12), 3449-3460. https://doi.org/10.1161/01.ATV.17.12.3449

Santiago-Torres, M., Tinker, L. F., Allison, M. A., Breymeyer, K. L., Garcia, L., Kroenke, C. H., Lampe, J. W., Shikany, J. M., Van Horn, L., \& Neuhouser, M. L. (2015). Development and use of a traditional Mexican diet score in relation to systemic inflammation and insulin resistance among women of Mexican descent. Journal of Nutrition, 145(12), 2732-2740. https://doi.org/10.3945/jn.115.213538

Shepherd, J., Packard, C. J., Patsch, J. R., Gotto, A. M., Jr., \& Taunton, O. D. (1978). Effects of dietary polyunsaturated and saturated fat on the properties of high density lipoproteins and the metabolism of apolipoprotein A-I. Journal of Clinical Investigation, 61(6), 15821592. https://doi.org/10.1172/JCI109078

Statulator. (2014). Sample size calculator for comparing two paired means. http://statulator.com/SampleSize/ss2PM.html

Stefan, N., Kantartzis, K., \& Häring, H.-U. (2008). Causes and metabolic consequences of fatty liver. Endocrine Reviews, 29(7), 939-960. https://doi.org/10.1210/er.2008-0009

Sullivan, G. M., \& Feinn, R. (2012). Using effect size — or why the $p$ value is not enough. Journal of Graduate Medical Education, 4(3), 279-282. https://doi.org/10.4300/JGMED-12-00156.1 
Tjepkema, M., Wilkins, R., Goedhuis, N., \& Pennock, J. (2012). Cardiovascular disease mortality among First Nations people in Canada, 1991-2001. Chronic Diseases and Injuries in Canada, 32(4), 200-207. https://doi.org/10.24095/hpcdp.32.4.04

Viguiliouk, E., Kendall, C. W. C., Mejia, S. B., Cozma, A. I., Ha, V., Mirrahimi, A., Jayalath, V. H., Augustin, L. S. A., Chiavaroli, L., Leiter, L. A., de Souza, R. J., Jenkins, D. J. A., \& Sievenpiper, J. L. (2014). Effect of tree nuts on glycemic control in diabetes: A systematic review and meta-analysis of randomized controlled dietary trials. PLoS ONE, 9(7), Article e103376. https://doi.org/10.1371/journal.pone.0103376

Von Korff, M., Ormel, J., Keefe, F. J., \& Dworkin, S. F. (1992). Grading the severity of chronic pain. Pain, 50(2), 133-149. https://doi.org/10.1016/0304-3959(92)90154-4

Waugh, F. W. (1916). Iroquois foods and food preparation. Geological Survey of Canada, Memoir No. 86. https://doi.org/10.4095/103487

Williams, K. H., Shackel, N. A., Gorrell, M. D., McLennan, S. V., \& Twigg, S. M. (2013). Diabetes and nonalcoholic fatty liver disease: A pathogenic duo. Endocrine Reviews, 34(1), 84-129. https://doi.org/10.1210/er.2012-1009

Willows, N. D. (2005). Determinants of healthy eating in Aboriginal Peoples in Canada: The current state of knowledge and research gaps. Canadian Journal of Public Health, 96(S3), S36-S41. https://doi.org/10.1007/BF03405199

Wong, J. M. W., Kendall, C. W. C., de Souza, R., Emam, A., Marchie, A., Vidgen, E., Holmes, C., \& Jenkins, D. J. A. (2010). The effect on the blood lipid profile of soy foods combined with a prebiotic: A randomized controlled trial. Metabolism: Clinical and Experimental, 59(9), 1331-1340. https://doi.org/10.1016/j.metabol.2009.12.017

Zhang, Q., Gonzalez de Mejia, E., Luna-Vital, D., Tao, T., Chandrasekaran, S., Chatham, L., Juvik, J., Singh, V., \& Kumar, D. (2019). Relationship of phenolic composition of selected purple maize (Zea mays L.) genotypes with their anti-inflammatory, antiadipogenic and anti-diabetic potential. Food Chemistry, 289, 739-750. https://doi.org/10.1016/j.foodchem.2019.03.116

Zulyniak, M. A., de Souza, R. J., Mente, A., Kandasamy, S., Nundy, M., Desai, D., Raman, K., Hasso, R., Pare, G., Beyene, J., \& Anand, S. S. (2016). A randomized controlled trial of the effects of a prudent diet on cardiovascular risk factors, gene expression, and DNA methylation - the Diet and Genetic Intervention (DIGEST) pilot study. BMC Nutrition, 2(1), Article 34. https://doi.org/10.1186/s40795-016-0074-6 


\section{Appendix A}

\section{Standardized Protocol for Physical Measures}

\begin{tabular}{|c|c|}
\hline Physical Measure & Instructions \\
\hline Height & $\begin{array}{l}\text { - Measure against a convenient, flat wall at the clinic site } \\
\text { - Subject must be barefoot or shoeless with arms hanging freely at the } \\
\text { side } \\
\text { - The heels of the feet must be together with the medial borders of the } \\
\text { feet at an angle of } 60 \text { degrees } \\
\text { - The shoulder blades, buttocks, and heels must be in contact with the } \\
\text { measuring wall } \\
\text { - The head is held in the Frankfort plane } \\
\text { - The measurement is recorded to the nearest } 0.1 \mathrm{~cm} \text { after the subject } \\
\text { inhales fully and maintains the erect position without altering the } \\
\text { load of the heels } \\
\text { - Record the obtained value on the space provided in the case report } \\
\text { form (CRF) }\end{array}$ \\
\hline $\begin{array}{l}\text { Weight and } \\
\text { Percent Body Fat }\end{array}$ & $\begin{array}{l}\text { - Ensure that the scale is calibrated prior to the clinic visit (a log } \\
\text { should be kept regarding the date of all completed calibrations) } \\
\text { - Ensure that the scale is "zeroed" before taking the weight } \\
\text { - The subject is measured in minimal clothing and must be barefoot } \\
\text { (for body fat) or shoeless with arms hanging freely at the side } \\
\text { - Record these values on space provided in the CRF }\end{array}$ \\
\hline $\begin{array}{l}\text { Waist } \\
\text { Circumference }\end{array}$ & $\begin{array}{l}\text { - The subject stands erect with the abdomen relaxed and arms at the } \\
\text { sides } \\
\text { - The measurement is taken over the abdomen at the smallest diameter } \\
\text { between the coastal margin and the iliac crest (the hip) } \\
\text { - This is best done with the study personnel facing the subject and } \\
\text { identifying the natural waist (i.e., the point of narrowing) } \\
\text { - The measurement is taken to the nearest } 0.1 \mathrm{~cm} \text { at the end of a } \\
\text { normal expiration, using a nonstretchable standard tape measure } \\
\text { attached to a spring balance exerting a force of } 750 \mathrm{~g} \\
\text { - The tape must be kept horizontal } \\
\text { - Record the measurement on the CRF }\end{array}$ \\
\hline Hip Circumference & $\begin{array}{l}\text { - The measurement is taken over minimal clothing at the level of the } \\
\text { greater trochanters (usually the widest diameter around the buttocks) } \\
\text { - The study personnel will bend by the side of the participant so that } \\
\text { the level of maximum extension of the buttocks is seen and the tape } \\
\text { measure can be read properly } \\
\text { - The measurement is taken to the nearest } 0.1 \mathrm{~cm} \text { using a } \\
\text { nonstretchable standard tape measure attached to a spring balance } \\
\text { exerting a force of } 750 \mathrm{~g} \\
\text { - The tape must be kept horizontal } \\
\text { - Record the measurement on the CRF }\end{array}$ \\
\hline
\end{tabular}




\begin{tabular}{|l|l|}
\hline $\begin{array}{l}\text { Resting Heart Rate } \\
\text { and Blood }\end{array}$ & $\begin{array}{l}\text { Two measurements are performed on the right arm using the Omron } \\
\text { automatic digital blood pressure monitor (Omron HEM-757) }\end{array}$ \\
Pressure & $\begin{array}{l}\text { Ensure that the batteries are charged } \\
\text { - Subject must be resting and calm for more than } 5 \text { minutes; should not } \\
\text { have smoked, exercised, or eaten in the last } 30 \text { minutes; and should } \\
\text { not have climbed stairs in the last 15-30 minutes before taking this } \\
\text { measurement }\end{array}$ \\
$\bullet \begin{array}{l}\text { Subject should be seated upright and relaxed with the right arm } \\
\text { supported at heart level } \\
\text { The measurement is taken using the brachial artery }\end{array}$ \\
$\qquad \begin{array}{l}\text { The readings should be recorded for systolic and diastolic pressures } \\
\text { and heart rate } \\
\text { Record exact values on the CRF provided; refrain from rounding }\end{array}$ \\
\hline
\end{tabular}




\section{Appendix B}

\section{Biological Sample Collection and Storage Protocols}

Serum risk factors. A nonfasting $19 \mathrm{~mL}$ blood sample was taken. It was processed locally and aliquots were shipped to a central biorepository, the Clinical Research Laboratory and Biobank, Population Health Research Institute, McMaster University (Hamilton, ON, Canada; CRLB) for analysis of apolipoproteins A1 and B (the major apolipoproteins on HDL-C and LDL-C), creatinine, and $\mathrm{HbA} 1 \mathrm{c}$.

Stool sample. Participants provided stool samples at the Month $-3,0$, and +3 visits. Participants defecated into a plastic commode and transferred $5 \mathrm{~g}$ (1 tablespoon) of fecal sample into a plastic pot. Samples were stored in a cooler bag with ice packs and kept in the freezer $\left(-20^{\circ} \mathrm{C}\right)$ until transported on dry ice to the CRLB where each was thawed quickly, and an aliquot was used for DNA isolation. Additional aliquots were stored at $-80^{\circ} \mathrm{C}$.

Additional sample. Participants consented to having additional fasting venous whole blood samples drawn and provided spot urine samples for future genetic, epigenetic, and metabolomic studies. The study nurse provided participants with the labelled $90 \mathrm{~mL}$ urine collection container and asked participants for a $30 \mathrm{~mL}$ urine specimen. All urine samples were aliquoted by a trained research nurse before being frozen and shipped to the CRLB.

Cardiovascular risk score. At the Month -3 visit, and after the intervention, we calculated each participant's INTERHEART risk score. This score considers age, the apolipoprotein B:A1 ratio, smoking, second-hand smoke exposure, diabetes, high blood pressure, waste-to-hip ratio, psychosocial factors, dietary factors, and physical activity. This score has been shown to predict myocardial infarction in the INTERHEART case-control study (Anand et al., 2016). Individuals were classified as low (0-9), moderate (10-15), or high (16-48) risk.

Mental health. Mental health was assessed with the Patient Health Questionnaire (PHQ-9), a multipurpose instrument for screening, diagnosing, monitoring, and measuring the severity of depression (Kroenke et al., 2001). It incorporates DSM-IV depression diagnostic criteria and is used in clinical practice.

Magnetic Resonance Imaging (MRI). Each participant received at least 2 MRI scans (one at either or both Month -3 and 0 visits, and one after the intervention) at a local facility (St. Joseph's Healthcare, Hamilton, ON) to detect cardiac and abdominal adipose tissue. MRI was chosen as the method of detection because of its specificity for underlying pathophysiology of cardiac, vascular, or cognitive dysfunction, test safety, clinical feasibility, accuracy, prognostic value, and potential impact on clinical decision-making. The abdominal MRI protocol is as follows: 
INTERNATIONAL JOURNAL OF INDIGENOUS HEALTH

\begin{tabular}{|l|l|l|}
\hline Abdominal MRI* & $\begin{array}{l}\text { Approximate imaging } \\
\text { time (minutes) }\end{array}$ & Outcome measure \\
\hline $\begin{array}{l}\text { T1w TSE abdominal } \\
\text { adipose tissue sequence }\end{array}$ & 2 & Visceral fat area \\
\hline $\begin{array}{l}\text { Liver 2D multi-echo } \\
\text { gradient-echo sequence }\end{array}$ & 1 & Hepatic fat fraction \\
\hline
\end{tabular}

* Varies depending on scanner make and model, hardware and software used for scanning, need for switching MR coils, participants' heart rate, and MRI technologist experience. 
Appendix C

Stability of Physical and Cardiovascular Risk Measures During Pre-Intervention Period

Note: $r=$ Pearson's product-moment correlation coefficient.

\begin{tabular}{|c|c|c|c|c|c|}
\hline Measure & $\begin{array}{c}n \text { at Month }-3, \\
n \text { at Month } 0\end{array}$ & $\begin{array}{c}\text { Month -3 } \\
M(S D)\end{array}$ & $\begin{array}{c}\text { Month 0 } \\
M(S D)\end{array}$ & $\begin{array}{c}n \\
\text { pairs }\end{array}$ & $r$ \\
\hline \multicolumn{6}{|l|}{ Physical measures } \\
\hline Weight $(\mathrm{kg})$ & 22,22 & $98.9(12.1)$ & $100.0(13.3)$ & 22 & .98 \\
\hline Body mass index $\left(\mathrm{kg} / \mathrm{m}^{2}\right)$ & 22,22 & $37.0(4.0)$ & $37.3(4.1)$ & 22 & .97 \\
\hline Body fat $(\%)$ & 22,22 & $47.0(2.8)$ & $47.3(2.9)$ & 22 & .91 \\
\hline Waist circumference $(\mathrm{cm})$ & 22,22 & $109.3(9.7)$ & $109.3(10.9)$ & 22 & .94 \\
\hline Hip circumference $(\mathrm{cm})$ & 22,22 & $118.4(7.4)$ & $117.9(7.3)$ & 22 & .88 \\
\hline Waist-to-hip ratio & 22,22 & $0.92(0.06)$ & $0.93(0.07)$ & 22 & .89 \\
\hline Mid-upper arm circumference $(\mathrm{cm})$ & 22,22 & $34.2(4.3)$ & $34.1(3.5)$ & 22 & .95 \\
\hline Calf circumference $(\mathrm{cm})$ & 22,22 & $40.4(3.9)$ & $40.5(4.0)$ & 22 & .98 \\
\hline Chest circumference $(\mathrm{cm})$ & 22,22 & $114.5(7.9)$ & $114.4(7.5)$ & 22 & .93 \\
\hline Neck circumference $(\mathrm{cm})$ & 22,22 & $36.5(3.1)$ & $36.5(3.2)$ & 22 & .99 \\
\hline Thigh circumference $(\mathrm{cm})$ & 22,22 & $57.0(5.3)$ & $57.4(5.1)$ & 22 & .92 \\
\hline Total body circumference $(\mathrm{cm})$ & 22,22 & $510.3(28.0)$ & $510.0(28.0)$ & 22 & .95 \\
\hline \multicolumn{6}{|l|}{ Cardiovascular risk factors } \\
\hline Systolic blood pressure $(\mathrm{mmHg})$ & 22,22 & $129.4(16.2)$ & $125.1(14.7)$ & 22 & .48 \\
\hline Diastolic blood pressure (mmHg) & 22,22 & $80.3(9.9)$ & $78.4(9.1)$ & 22 & .66 \\
\hline Heart rate $(\mathrm{bpm})$ & 22,22 & $69.2(12.9)$ & $71.8(9.5)$ & 22 & .46 \\
\hline Creatinine $(\mu \mathrm{mol} / \mathrm{L})$ & 21,9 & $70.7(12.5)$ & $69.6(11.4)$ & 9 & .74 \\
\hline Apolipoprotein-B (Apo-B; g/L ) & 21,9 & $0.99(0.19)$ & $0.94(0.14)$ & 9 & .88 \\
\hline Apolipoprotein-A1 (Apo-A1; g/L) & 21,9 & $1.38(0.25)$ & $1.34(0.26)$ & 9 & .95 \\
\hline Apo-B:Apo-A1 & 21,9 & $0.74(0.19)$ & $0.72(0.17)$ & 9 & .95 \\
\hline Hemoglobin A1c (\%) & 21,9 & $5.7(0.6)$ & $5.7(0.4)$ & 9 & .97 \\
\hline \multicolumn{6}{|l|}{ Ectopic adipose tissue measures } \\
\hline Subcutaneous adipose tissue (SAT; $\mathrm{mL})$ & 12,7 & $228.2(52.2)$ & $234.4(29.2)$ & 4 & .67 \\
\hline Visceral adipose tissue (VAT; $\mathrm{mL}$ ) & 18,8 & $103.3(37.2)$ & $102.0(29.6)$ & 7 & .77 \\
\hline SAT:VAT & 12,7 & $2.6(1.3)$ & $2.2(0.5)$ & 4 & .86 \\
\hline Cardiac adipose tissue (CAT; $\mathrm{mL})$ & 17,9 & $23.2(7.9)$ & $21.5(7.7)$ & 8 & -.07 \\
\hline Hepatic fat fraction (HFF; \%) & 20,10 & $11.8(10.7)$ & $11.3(8.6)$ & 9 & .95 \\
\hline
\end{tabular}

